\title{
CAMBIOS EN LA POBLACIÓN DE LOS MUNICIPIOS \\ DE HASTA 5000 HABITANTES DE ESPAÑA (2000-2019): \\ UNA APROXIMACIÓN A LA CRISIS DEMOGRÁFICA \\ EN EL TERRITORIO RURAL
}

\author{
Xosé Elías Trabada Crende \\ xetc@emic-etic.eu \\ Universidad de Vigo y Consultora Emic-Etic
}

\section{RESUMEN}

El territorio rural español del interior peninsular se encuentra inmerso en una grave crisis demográfica que amenaza la supervivencia de una parte relevante de sus municipios. Durante las casi dos décadas transcurridas del siglo xxi no se han corregido las tendencias de despoblación y abandono, de envejecimiento y masculinización de la población rural, sino que se han cronificado para derivar en un intenso proceso de desertización demográfica del hábitat rural segregado de las redes y actividades de la globalización capitalista. Urge un cambio copernicano en las políticas de ordenación y planificación del territorio, mediante el cual se ha de promover una reforma de la Administración local hacia la constitución federal de comarcas y un ecodesarrollo endógeno e integral que, básicamente, rejuvenezca la población rural gracias a la inmigración.

Palabras clave: municipios rurales, despoblación, sobreenvejecimiento, masculinización, desertización demográfica.

CHANGES IN THE POPULATION OF THE MUNICIPALITIES

WITH LESS THAN 5000 INHABITANTS IN SPAIN (2000-2019):

AN APPROACH TO THE DEMOGRAPHIC CRISIS IN THE RURAL TERRITORY

\section{Abstract}

The Spanish rural territory of the peninsular interior is immersed in a serious demographic crisis that threatens the survival of a relevant part of its municipalities. During the almost two decades of the 21st century, the trends of depopulation and abandonment, of aging and masculinization of the rural population have not been corrected, but have been chronified to lead to an intense process of demographic desertification of the rural habitat segregated from networks and activities of capitalist globalization. A Copernican change in territorial planning and planning policies is urgently needed, promoting a reform of the Local Administration towards the federal constitution of Comarcas and an endogenous and integral ecodevelopment that basically rejuvenates the rural population thanks to the immigration.

KEYWORDs: rural municipalities, depopulation, over-aging, masculinization, demographic desertification. 


\section{PRESENTACIÓN}

La mayoría de nuestros municipios rurales de la España peninsular han continuado sufriendo un proceso de despoblación y abandono durante las dos décadas transcurridas del siglo xxi, que es estructural y parece irreversible, el cual ha alcanzado en muchos de ellos un grado de gravedad propio de un 'desierto demográfico', que debilita y amenaza la supervivencia misma de las comunidades locales más afectadas. Con este artículo, pretendemos dar a conocer la magnitud cuantitativa del proceso demográfico que desertiza el territorio rural del Estado español, centrando nuestra mirada de sociología de la población en el intervalo temporal de 2000 a 2019 y en los municipios españoles de hasta 5000 habitantes, pero con un enfoque comparativo con los municipios que superan dicho umbral de poblamiento. Además de la despoblación, nos interesamos por los fenómenos demográficos del envejecimiento, la masculinización y la inmigración extranjera, así como de la densidad de población en el territorio, con el propósito de conocer su evolución y dimensión cuantitativa entre los municipios de hasta 5000 habitantes y, a su vez, indagamos en qué rasgos de esos fenómenos se diferencian con respecto a los municipios de más de 5000 habitantes.

Sin embargo, el objetivo de nuestro artículo no se limita a conocer la dimensión cuantitativa de la crisis demográfica que debilita y amenaza la supervivencia de una parte relevante de los municipios rurales del interior peninsular, sino que también queremos reflexionar sobre su dimensión cualitativa en un sentido propositivo. Parafraseando la famosa tesis undécima de Marx sobre Feuerbach, apreciamos que las y los sociólogos explicamos la realidad rural de diferentes maneras, pero también debemos esforzarnos por contribuir a cambiarla. Por consiguiente, hemos elaborado este artículo con la finalidad estratégica de 'conocer para actuar', ya que pensamos que la sociología no solo ha de ser una disciplina científica con carácter semántico, sino también pragmático: su interés respecto del objeto de estudio tiene que abarcar las vertientes del 'decir' y del 'hacer', aunando las perspectivas distributiva y estructural con el enfoque dialéctico (Ibáñez, 1991). De ahí que finalicemos este artículo con un apartado dedicado a recomendar varias propuestas dirigidas a actuar contra la crisis demográfica que sufre el mundo rural.

En cuanto a la metodología empleada, realizamos un análisis secundario demográfico de los datos cuantitativos generados por dos fuentes secundarias: la Estadística del Padrón Continuo, con referencia temporal a 1 de enero de 2000 y 2019, y los Censos de Población y Viviendas, principalmente los comprendidos de 1981 a 2011, ambas fuentes del Instituto Nacional de Estadística (INE). En líneas generales, efectuamos un análisis secundario de carácter demográfico de varios indicadores con relación a la cantidad y evolución de la población total, la estructura por edad (edades medias, porcentajes de menores de 15 años y de mayores de 64 años, índices de envejecimiento), la estructura por sexo (evolución y ratios de masculinidad), la población total según su nacionalidad (porcentajes de población extranjera), además de analizar la densidad de habitantes por $\mathrm{km}^{2}$. Indicadores cuantitativos que se refieren a los municipios españoles distribuidos en estratos según su tamaño 
poblacional, un tipo de clasificación que utiliza el INE en la explotación estadística de los Censos de Población y del Padrón Continuo.

El tamaño demográfico de los municipios se aprecia en sociología y geografía como uno de los criterios principales para caracterizar los territorios rural y urbano, estableciéndose generalmente un umbral o límite concreto para adscribir a un municipio en uno u otro tipo de hábitat. De la clasificación estadística que realiza el INE con los municipios españoles según su tamaño demográfico, hemos optado por hasta 5000 habitantes como el umbral por debajo del cual es bastante probable que nos encontremos ante municipios rurales, pues desde 5001 a 10000 habitantes pensamos que aumenta la posibilidad de que se trate de 'municipios híbridos o mixtos', donde se combinan atributos rurales y urbanos (los espacios rururbano y periurbano). Somos conscientes de que la variable del tamaño demográfico, siendo pertinente y adecuada, sin embargo es insuficiente para definir un municipio como rural o urbano, ya que debería complementarse con otras variables, como el grado de urbanización y de densidad demográfica y la estructura económica. En todo caso, pensamos que entre los municipios españoles de hasta 5000 habitantes se encuentran la gran mayoría de los que realmente son rurales ${ }^{1}$, incluyendo los que son cabeceras de una comarca rural, los cuales no debemos excluirlos del medio rural por el simple hecho de desempeñar ese rol de centralidad en el territorio, lo que de manera mecánica se suele identificar como un atributo exclusivo del hábitat urbano.

Finalicemos la presentación del artículo mencionando que se desagrega en ocho apartados: despoblación y abandono, el sobreenvejecimiento de la estructura por edad, la masculinización de la estructura por sexo, la inmigración extranjera, las pirámides de población, un desierto demográfico, conclusiones y algunas recomendaciones.

\section{DESPOBLACIÓN Y ABANDONO}

Comencemos por los datos estadísticos del Padrón Continuo de 1 de enero de 2019 (datos definitivos), donde observamos que el conjunto de los municipios de hasta 5000 habitantes sufrió un ligero decremento de $-0,2 \%$ con respecto a la población total empadronada en el año anterior: en términos absolutos, sus residentes menguaron en 11058 efectivos. A diferencia del conjunto de los municipios de más de 5000 habitantes, cuya población empadronada aumentó en 314286 individuos, significando un incremento del $0,8 \%$, que es responsable del crecimiento interanual experimentado por la totalidad de la población de España $(0,6 \%)$.

${ }^{1}$ En el artículo 3 de la Ley 45/2007 de 13 de diciembre, para el Desarrollo Sostenible del Medio Rural (LDSMR), se define el 'medio rural' como el espacio geográfico formado por la agregación de municipios o entidades locales menores definido por las administraciones competentes que posean una población inferior a 30000 habitantes y una densidad inferior a los 100 habitantes por $\mathrm{km}^{2}$. Además, define el «municipio rural de pequeño tamaño» como el que posea una población residente inferior a los 5000 habitantes y esté integrado en el medio rural. 


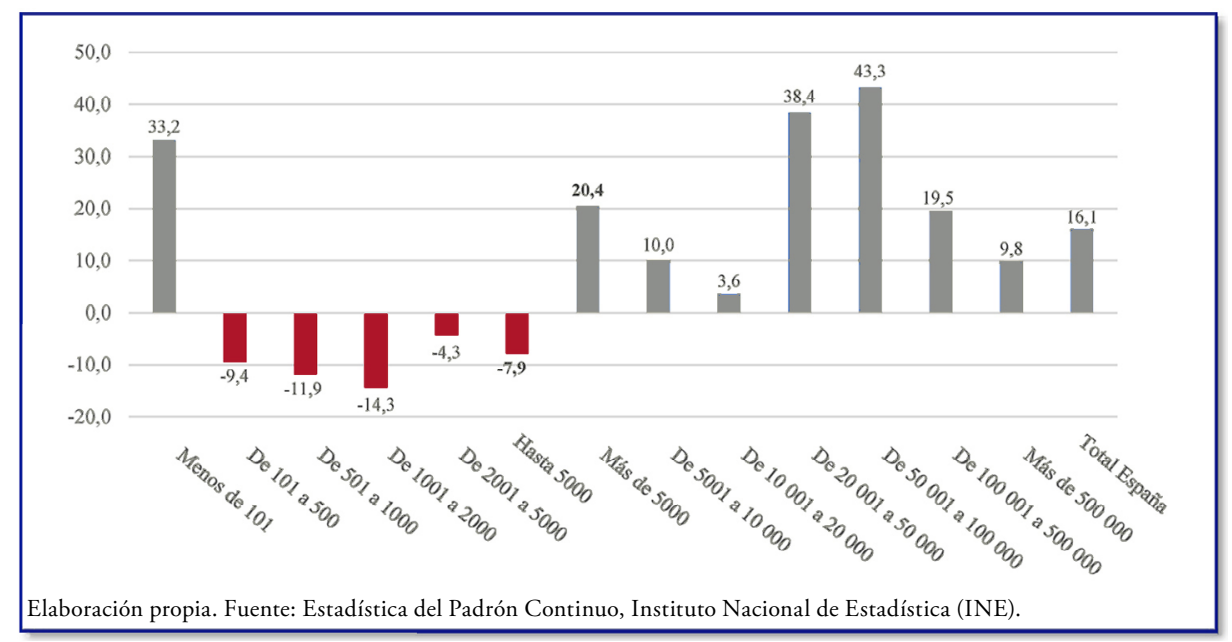

Gráfico 1. Evolución de la población, ambos sexos, entre el 1 de enero de 2000 y 2019 en el Padrón Continuo (datos definitivos) de los municipios españoles clasificados por tamańo demográfico: incrementos (\%) o decrementos (-\%).

Al contemplar la evolución entre el 1 de enero de 2000 y 2019, se observa con mayor nitidez la desigual dinámica demográfica que ha actuado en los dos conjuntos municipales: la población empadronada en los de hasta 5000 habitantes decreció en $-7,9 \%$, mientras en los municipios que superaron ese umbral creció en $20,4 \%$. Entre los términos municipales que suponemos rurales ( $\leq 5000$ residentes) se manifiesta una única excepción a la corriente dominante de declive demográfico: la población sí aumentó entre los de menos de 101 habitantes $(+33,2 \%)$, aunque más bien se debe a que creció el número de municipios que se precipitaron a este pequeño tamaño, motivado por el intenso proceso de despoblación y abandono que sufre el medio rural con una demografía inferior y más debilitada. Por el contrario, la población empadronada sí creció en cada uno de los seis tramos en los que el INE clasifica los términos municipales que superan los 5000 habitantes, como podemos observar en el gráfico 1 .

En un escenario estatal de crecimiento demográfico (16,1\%) entre el 1 de enero de 2000 y 2019, el declive de residentes en los municipios de hasta 5000 habitantes ha implicado que estos perdiesen representación en el total de la población española. Así, su significación menguó en casi tres puntos porcentuales: del 15,3\% en 2000 al 12,1\% en 2019. De hecho, sobre el total estatal, entre el 1 de enero de 2000 y 2019 creció la representación relativa de los tramos municipales de 20001 a 50000 (de 13,9\% a 16,5\%), de 50001 a 100000 (de 10,5\% a 12,9\%) y, ligeramente, de 100001 a 500000 habitantes (de 23,1\% a 23,8\%). Por consiguiente, se acrecentó la relevancia poblacional de los municipios propiamente urbanos (ver tabla I), en general de las ciudades pequeńas y medianas, pero no así de las grandes 
urbes y metrópolis que superan los 500000 habitantes. En suma, durante el tiempo transcurrido del siglo XXI, ha proseguido la concentración de la población en el territorio urbano $^{2}$, donde se centralizan las actividades económicas, los empleos y servicios, tanto privados como públicos, de la formación social española.

Ahora bien, ¿̇cuántos municipios tienen menos de 5001 habitantes? Al comenzar el año 2019, de los 8131 municipios españoles existentes, 6829 no superaron ese umbral de poblamiento; en términos porcentuales, representan el $84 \%$ del total. Además, casi dos tercios de los municipios espańoles - concretamente 5000, que simbolizan el 61,5\% del total- no lograron superar los 1000 habitantes. Asimismo, prácticamente la mitad de nuestro universo municipal -precisamente 3997 municipios, que significan el 49,2\% del total- no consiguieron rebasar los 500 residentes. Y nada menos que 1352 términos municipales no superaron el nivel más bajo de poblamiento, esto es, hasta 100 habitantes, los cuales representan el 16,6\% del total municipal.

\begin{tabular}{|c|c|c|c|c|c|c|}
\hline $\begin{array}{r}\text { TABLA I. DISTRII } \\
\text { Y DE } 2019 \text { EN } \\
\text { DEMOG }\end{array}$ & $\begin{array}{l}\text { EA PADRÓN } \\
\text { RÁFICO DI }\end{array}$ & $\begin{array}{l}\text { ONTINU } \\
\text { MUNICI }\end{array}$ & $\begin{array}{l}\text { (DATOS I } \\
\text { O: \% RESI }\end{array}$ & $\begin{array}{l}\text { FINITIVO } \\
\text { CTO TOTA }\end{array}$ & EGÚN TA & $\begin{array}{l}\text { DE } 2000 \\
\text { AÑO }\end{array}$ \\
\hline Tramos municipales & $\begin{array}{c}\text { N. }{ }^{\circ} \\
\text { Municipios } \\
01 / 01 / 2000\end{array}$ & $\begin{array}{l}\text { POBLACIÓN } \\
01 / 01 / 2000\end{array}$ & $\begin{array}{c}\% \\
\text { Pob. EsPAÑa } \\
01 / 01 / 2000\end{array}$ & $\begin{array}{c}\text { N. }{ }^{\circ} \\
\text { Municipios } \\
01 / 01 / 2019\end{array}$ & $\begin{array}{l}\text { PoBLACIÓN } \\
01 / 01 / 2019\end{array}$ & $\begin{array}{c}\% \\
\text { Poв. EsPAÑA } \\
01 / 01 / 2019\end{array}$ \\
\hline Menos de 101 habitantes & 928 & 57677 & 0,14 & 1352 & 76828 & 0,16 \\
\hline De 101 a 500 & 2879 & 726261 & 1,79 & 2645 & 658384 & 1,40 \\
\hline De 501 a 1000 & 1148 & 818273 & 2,02 & 1003 & 721203 & 1,53 \\
\hline De 1001 a 2000 & 1005 & 1450856 & 3,58 & 877 & 1242862 & 2,64 \\
\hline De 2001 a 5000 & 996 & 3134288 & 7,74 & 952 & 3000351 & 6,38 \\
\hline Hasta 5000 hab. & 6956 & 6187355 & 15,28 & 6829 & 5699628 & 12,12 \\
\hline Más de 5000 hab. & 1148 & 34312436 & 84,72 & 1302 & 41326580 & 87,88 \\
\hline De 5001 a 10000 & 511 & 3515907 & 8,68 & 549 & 3865826 & 8,22 \\
\hline De 10001 a 20000 & 329 & 4622754 & 11,41 & 340 & 4787781 & 10,18 \\
\hline De 20001 a 50000 & 190 & 5609225 & 13,85 & 265 & 7765329 & 16,51 \\
\hline De 500001 a 100000 & 63 & 4241165 & 10,47 & 85 & 6075765 & 12,92 \\
\hline De 100001 a 500000 & 49 & 9368333 & 23,13 & 57 & 11196460 & 23,81 \\
\hline Más de 500000 & 6 & 6955052 & 17,17 & 6 & 7635419 & 16,24 \\
\hline Total España & 8104 & 40499791 & 100,00 & 8131 & 47026208 & 100,00 \\
\hline
\end{tabular}

Elaboración propia. Fuente: Estadística del Padrón Continuo, Instituto Nacional de Estadística (INE).

${ }^{2}$ Los 118 municipios que, a 1 de enero de 2000, superaron los 50000 habitantes sumaron 20564550 personas empadronadas ( $50,8 \%$ de la población total), aumentando a 148 municipios los que consiguieron superar dicho umbral demográfico en el Padrón Continuo de 1 enero de 2019 (datos definitivos, INE), los cuales acogieron 24907644 personas empadronadas (53\% de la población total). 


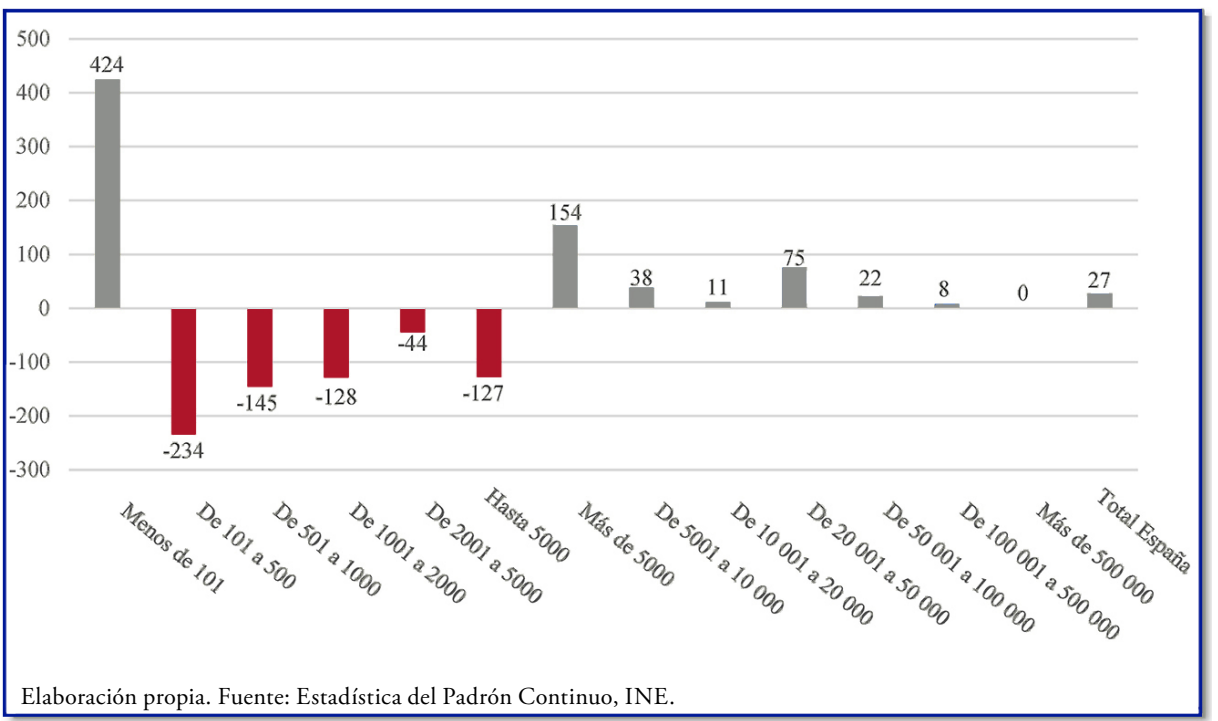

Gráfico 2. Diferencia en el número de municipios españoles clasificados según tamaño demográfico entre el 1 de enero de 2000 y 2019 en el Padrón Continuo (datos definitivos).

Aparte de eso, entre 2000 y 2019 se produjo un notorio desplazamiento de municipios hacia el tramo con menor poblamiento (ver gráfico 2 ): el número de términos municipales con menos de 101 habitantes aumentó en 387 unidades (de 928 a 1352), un incremento del $45,7 \%$ durante el tiempo que transcurrió del siglo XXI, en el que solamente se crearon 27 nuevos municipios en el Estado español (+0,3\%). Al mismo tiempo, disminuyó el número de municipios comprendidos en los cuatro tramos de 101 a 5000 habitantes, con un retroceso global de 551 términos, los cuales simbolizan un decremento de $-9,8 \%$. En resumen, estos datos nos advierten del imparable avance del proceso de despoblación y abandono entre los municipios rurales que, a su vez, está exacerbando el problema de la atomización municipal española.

\section{EL SOBREENVEJECIMIENTO DE LA ESTRUCTURA POR EDAD}

El proceso continuado y selectivo de despoblación (sobre todo, de jóvenes y adultos) ha generado una estructura de edad envejecida en el territorio rural que no es rururbano o periurbano, alejado de las urbes y segregado de las redes económicas de la globalización capitalista. En un contexto demográfico general de avance 


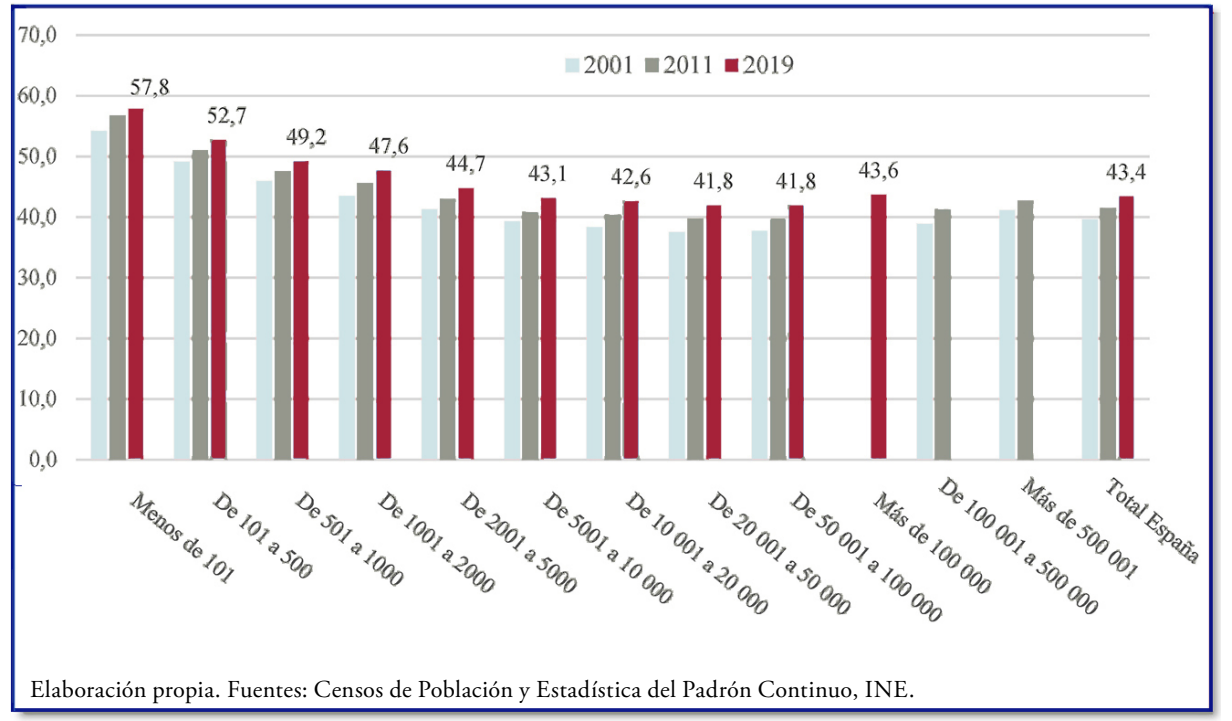

Gráfico 3. Edades medias de la población, ambos sexos, en los Censos de Población de 2001 y 2011 y en el Padrón Continuo de 2019 (datos provisionales) en los municipios españoles según tamaño demográfico.

del proceso de envejecimiento ${ }^{3}$, los municipios de hasta 5000 habitantes son los más afectados: de hecho, se manifiesta una clara relación inversa entre el tamaño demográfico de los municipios y la edad media de la población (EMP). Esto es, cuanto menor es el tamaño, mayor resulta la EMP de ambos sexos. En la Estadística del Padrón Continuo de 1 de enero 2019 (datos provisionales ${ }^{4}$ ), se percibe con claridad dicha asociación inversa (ver gráfico 3): en los municipios de menos de 101 habitantes, la EMP para ambos sexos es de 57,8 ańos, mientras entre los municipios que superaron los 100000 habitantes su valor se reduce a 43,6 años; nada menos que 14,2 años de diferencia en la EMP entre los dos polos del tamaño municipal.

En cuanto a la variable sexo, en el Padrón Continuo de 1 de enero de 2019 (datos provisionales), las edades medias de las mujeres superaron las respectivas de

3 Como expresa la demógrafa Inmaculada Santos: «Así, entiendo por envejecimiento demográfico la modificación progresiva de la estructura por edad de la población, que se traduce en un aumento de la proporción de los grupos de edad avanzada, frente a una disminución pareja de los grupos de edad más joven, o, lo que es igual, la proporción creciente del grupo de edad 65 ańos y más respecto del total de la población» (Santos, 1996: 178).

${ }^{4}$ El INE publica el cruce de la edad media de la población según el tamaño del municipio y el sexo en los datos provisionales de la Estadística del Padrón Continuo, pero no para sus datos definitivos. 


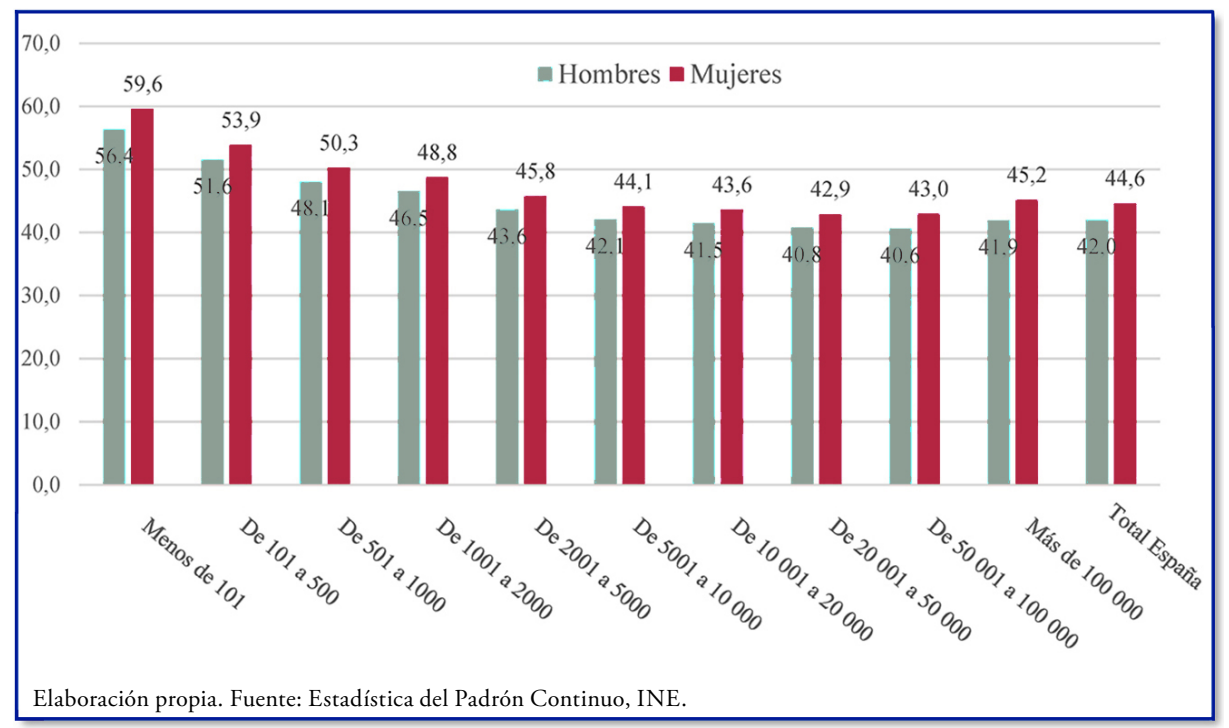

Gráfico 4. Edades medias de la población según sexo en el Padrón Continuo de 2019 (datos provisionales) en los municipios españoles por tamaño demográfico.

los hombres en cada uno de los tramos municipales, unas diferencias favorables para las mujeres que abarcan entre 2 años (de 5001 a 10000 ) y 3,3 años (más de 100000 habitantes), como consecuencia de la mayor longevidad femenina o, desde la vertiente del otro género, por la sobremortalidad masculina. Además, en el gráfico 4, de nuevo observamos que el envejecimiento es un fenómeno demográfico que afecta en mayor medida a los municipios rurales, ya que las edades medias de hombres y mujeres en los cinco tramos de menos de 5001 habitantes son notoriamente más altas con relación a las edades medias por sexo correspondientes a los cinco tramos municipales de más de 5000 habitantes.

En general, la estructura por edad de los municipios de menos de 5001 habitantes se manifiesta visiblemente más envejecida debido a la persistente y selectiva corriente emigratoria que ha despoblado la mayoría de los municipios rurales, fundamentalmente desde la segunda mitad del siglo xx. La emigración masiva de efectivos de las cohortes de la juventud y adultez durante el éxodo rural del segundo franquismo, no solamente despojó a los municipios rurales afectados de la capacidad socioeconómica de las y los emigrantes, sino también de la de renovar y aumentar su demografía, que derivó a continuación en una estructura por edades que se envejeció con precocidad.

Resaltar que el movimiento emigratorio desde los municipios rurales ha continuado durante el actual régimen democrático de monarquía parlamentaria, aunque en cantidades menores, debido al importante despoblamiento y debilitamiento de su capacidad de renovación demográfica que provocó el éxodo rural franquista (ver gráfico 5). En este sentido, de 1981 a 2019 (datos definitivos del Padrón Con- 


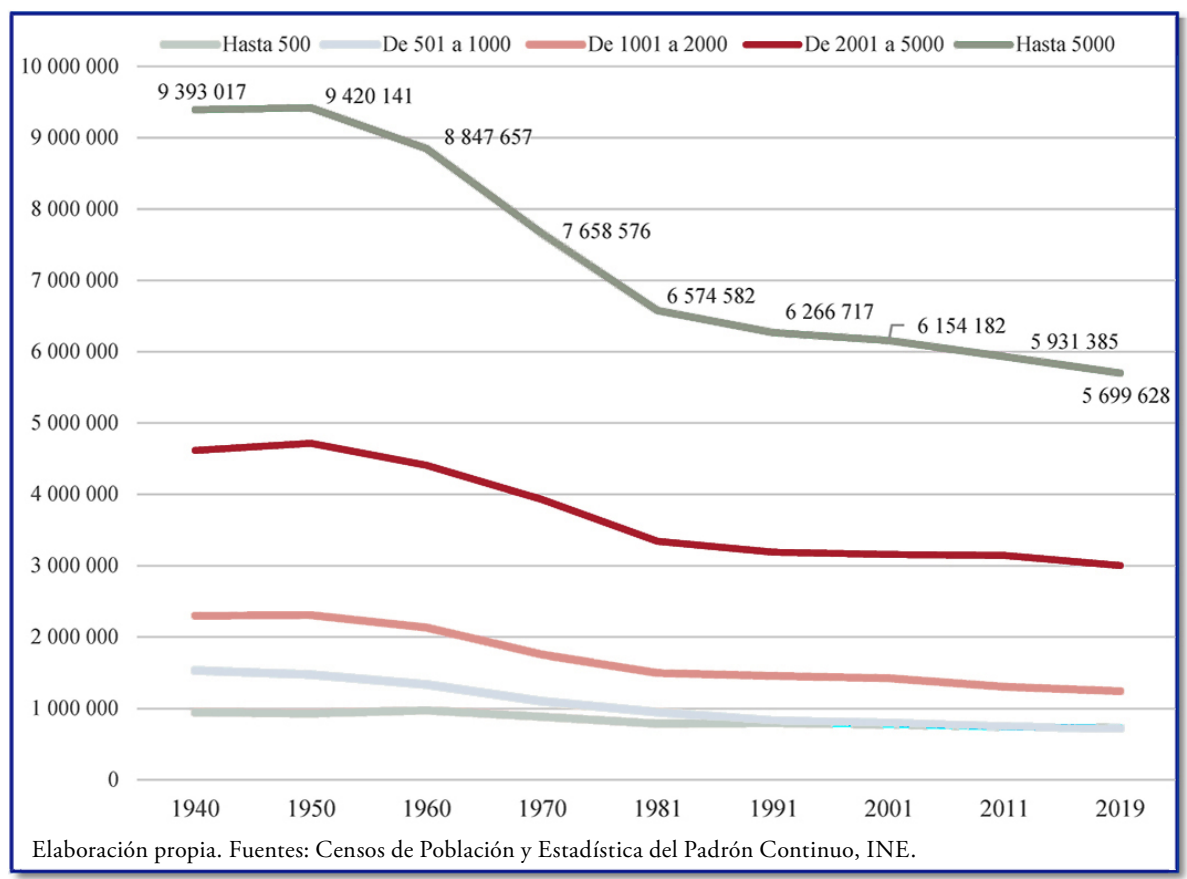

Gráfico 5. Evolución de la población, ambos sexos, entre 1940 y 2019

(datos definitivos) según tramos municipales por tamaño hasta 5000 habitantes.

tinuo), los municipios de hasta 5000 habitantes decrecieron demográficamente un $-13,3 \%$ y, en términos absolutos, en 874954 residentes, mientras entre 1950 y 1981 disminuyeron sus pobladores en 2845559 personas, que representan en términos porcentuales un declive demográfico del $-30,2 \%$ de sus residentes de partida. Si en el segundo período temporal distinguimos entre los subperíodos de 1981-2001 y 2001-2019, conocemos que durante el primero la población de los municipios de hasta 5000 habitantes decreció un $-6,4 \%$ y durante el segundo un $-7,4 \%$, unos decrementos que significan en números absolutos 420400 y 454554 habitantes, respectivamente. Por tanto, el problema demográfico en los municipios rurales se ha cronificado y agravado durante las dos décadas transcurridas del siglo Xx.

En líneas generales, la emigración rural durante las últimas décadas ha sido más limitada y selectiva, nutriéndose en mayor medida de personas jóvenes y adultas con estudios posobligatorios y superiores (FP de grado superior y titulaciones universitarias). Sin embargo, su impacto cualitativo ha sido bastante negativo para el mundo rural, pues le ha despojado de buena parte de los sujetos sociodemográficos, a priori, más capacitados para idear, organizar y dirigir un cambio sociocultural y económico que revalorice el espacio rural y promueva un discurso crítico y una política alternativa para el reequilibrio de las relaciones entre el campo y la ciudad, actualmente dominadas por la segregación, la discriminación y la desigualdad 
estructural, en las que el territorio rural se ve sometido al urbano, especialmente al metropolitano, sujeto a una especie de neocolonialismo 5 .

Reflexionemos un momento en la emigración de las y los jóvenes, los cuales suelen adquirir una educación y formación superior a la de sus padres y madres, y con frecuencia tienden a emigrar debido a que las oportunidades de empleo existentes en el mercado de trabajo comarcal están bastante limitadas a oficios y ocupaciones de menor cualificación. La escasa transformación e industrialización agroalimentaria en muchas comarcas rurales ha impedido el crecimiento de ocupaciones técnicas, de gestión-dirección o de servicios a las empresas en las que se hubiesen insertado laboralmente parte de las y los jóvenes rurales con titulaciones superiores que se han visto obligados a emigrar por escasear los puestos de trabajo de nivel medio y superior adecuados a sus perfiles educativos-formativos.

En el ambiente rural de las explotaciones familiares, mediatizado por valores patriarcales y androcéntricos, con frecuencia se espera que sea un hijo varón el que continúe con la actividad económica, pero un cúmulo de condicionantes negativos ha provocado un bloqueo y crisis en el relevo generacional (Trabada et al., 2007; Trabada, 2019). Por otro lado, ciertos valores y actitudes de padres y madres fomentan el fenómeno de la emigración juvenil: desean para sus hijos e hijas una formación educativa y una trayectoria profesional de cuello blanco, de grado medio o superior. Infravaloran los oficios agropecuarios, ya que los perciben como carentes de estatus y prestigio social. Generalmente, están influenciados por un proceso de aculturación que les genera desafección por sus oficios y formas de vida rurales $\mathrm{y}$ atracción por las urbanas.

En cuanto a las mujeres jóvenes, también emigran a las urbes para buscar un escenario social más propicio para la satisfacción de sus deseos y aspiraciones de desarrollo personal, mediante unas relaciones menos condicionadas por la desigualdad entre géneros ${ }^{6}$. Parece que el poder de los viejos valores y prácticas patriarcales y androcéntricas se resiste en el espacio rural con mayor firmeza al poder emergente de los nuevos valores y prácticas igualitarias entre géneros, en cierta medida

${ }^{5}$ En el período actual neofordista o posfordista del desarrollo capitalista, la desigualdad campo-ciudad está basada en el control y explotación indirecta que ejercen las grandes agroindustrias y empresas de distribución-comercialización de productos alimentarios, generalmente con su sede social y mayoría de accionistas en áreas urbanas-metropolitanas, sobre las explotaciones agropecuarias familiares a través de los mercados de insumos (fertilizantes, agroquímicos, semillas, maquinaria y equipos técnicos) y los mercados de productos agrarios en origen y de consumo final. Este dominio indirecto que ejercen las grandes agroindustrias y empresas de distribución-comercialización sobre el territorio rural, en el que el sector agrícola aún es relevante, no es muy diferente del que ejercen los países capitalistas más desarrollados a través de sus empresas multinacionales sobre los países de la semiperiferia y la periferia del capitalismo globalizado. A diferencia de las relaciones colonialistas, donde el control y la explotación son directos, en las relaciones neocoloniales tienden a ser indirectos, generalmente a través del mecanismo de precios de los mercados y los intercambios comerciales desiguales.

${ }^{6}$ Esta emigración de las jóvenes rurales nos recuerda el antiguo aforismo medieval de origen germánico «el aire de la ciudad te hace libre». 
una consecuencia de la estructura por edad más envejecida (el efecto generación). Por ejemplo, en la titularidad de las explotaciones agrarias familiares, el 67,6\% de las personas titulares son hombres por el 32,4\% de mujeres, según la Encuesta sobre la estructura de las explotaciones agricolas de 2016 (INE). Unos datos que reflejan la problemática de la desigualdad de género y la invisibilidad del trabajo femenino en el sector agrario, donde parte de las mujeres, que son trabajadoras agrícolas y cónyuges de varones que desempeñan el rol de titulares jefes de explotaciones familiares agrarias, son relegadas a la situación de 'ayuda familiar' en vez de apreciarse como cotitulares jefas de la explotación?

Regresemos al análisis demográfico de los resultados de los Censos de Población y del Padrón Continuo (datos definitivos): en el Censo de 1981, el primero realizado durante el actual régimen de monarquía parlamentaria, ya se percibía con claridad que la estructura por edades de la población de los municipios de menos de 5001 habitantes mostraba un grado de envejecimiento mayor con relación a la población que residía en los municipios que superaban ese tamaño demográfico. En concreto, las y los mayores de 64 años significaron el 16,3\% de la población total censada en el primer conglomerado municipal, mientras el porcentaje de envejecimiento se redujo al 10,2\% entre la población censada en los municipios de más de 5000 residentes. Este mayor grado de envejecimiento de la población en los municipios de menos de 5001 habitantes se intensificó en los siguientes Censos de Población (ver gráfico 6): 19,9\% sobre 12,7\% en 1991 y $24 \%$ sobre $15,5 \%$ en 2001 , mientras en el último Censo de 2011 el porcentaje de envejecimiento fue de 23,3\% en los municipios de menos de 5000 residentes sobre 16,1\% en los de más de 5000 . Pero al inicio de 2019 se observa que el porcentaje de envejecimiento vuelve a crecer en los municipios de menos de 5000 habitantes, manteniéndose casi estable en los de más de 5000: 24,8\% sobre 16,3\%.

En resumen, aunque las poblaciones de los dos conjuntos municipales comparten el progreso del fenómeno del envejecimiento, sin embargo, ha avanzado con bastante más ímpetu entre los municipios de menos de 5001 habitantes. En concreto, a 1 de enero de 2019, las y los mayores de 64 años duplicaron a las y los menores de 15 años empadronados en los municipios de menos de 5000 habitantes (203 por cada 100), mientras entre los municipios que superaron ese umbral de poblamiento, el índice de envejecimiento solo se mostró moderadamente favorable para las personas de 65 y más años (123 por cada 100). En síntesis, la estructura de edad de la población rural, más que envejecida, está sobreenvejecida.

Por lo demás, la desaceleración del proceso de envejecimiento entre los Censos de Población de 2001 y 2011 seguramente estuvo motivada por los flujos de la inmigración extranjera, cuya estructura por edades se distingue por ser más joven

7 En el Registro de Titularidad Compartida de Explotaciones Agrarias (RETICOM), a 31 de diciembre de 2019, solamente se contabilizaron un total acumulado de 631 explotaciones con titularidad compartida. La Ley 35/2011, de 4 de octubre, sobre titularidad compartida de las explotaciones agrarias entró en vigor el 5 de enero de 2012 y el Registro RETICOM se regula por la Orden AAA/1408/2012 de 26 de junio (fuente: Titularidad compartida en las explotaciones agrarias, MAPA). 


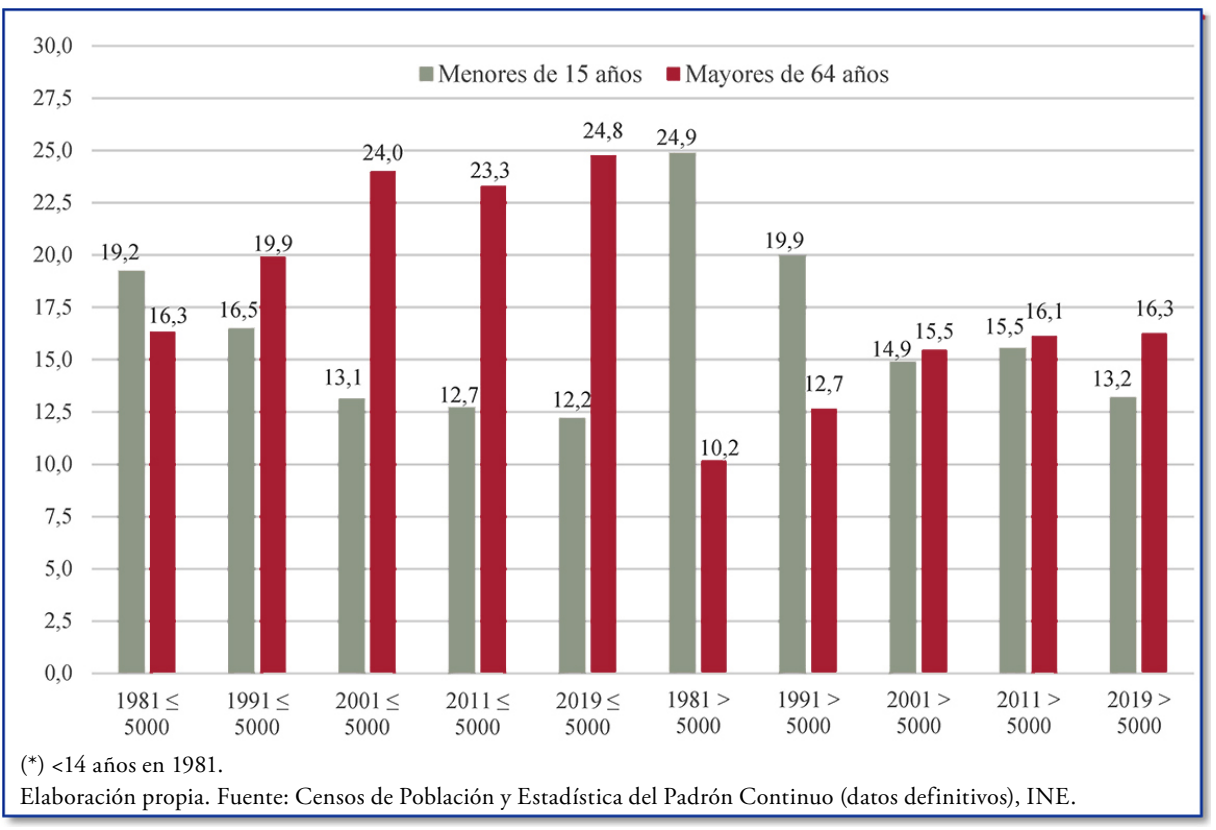

Gráfico 6. Porcentajes que representan las cohortes de $<15$ años y de $>$ de 64 años, ambos sexos, sobre total de la población en los municipios de hasta 5000 y de más de 5000 habitantes en los Censos de $1981\left(^{*}\right), 1991,2001$ y 2011 y Padrón Continuo 2019.

que la respectiva de la población de nacionalidad española. Efectivamente, según el Censo de 2011 y para ambos sexos, la edad media de la población extranjera era de 34,1 años frente a 42,2 años en la española. Asimismo, en todos los estratos municipales definidos por su tamaño demográfico, la EMP extranjera fue visiblemente inferior con respecto a la EMP española, si bien las diferencias más elevadas se expresaron en los estratos municipales de menor tamaño poblacional, normalmente correspondientes al medio rural, como se observa en el gráfico 7. En suma, las y los nuevos vecinos de nacionalidad extranjera han contribuido, sin lugar a duda, a frenar o mitigar el proceso de sobreenvejecimiento que sufre la población rural.

\section{LA MASCULINIZACIÓN DE LA ESTRUCTURA POR SEXO}

Normalmente, una población con una estructura por edad afectada por el proceso de envejecimiento suele tener una distribución entre sexos escorada hacia las mujeres, debido a su mayor longevidad o por la sobremortalidad masculina. No obstante, el movimiento migratorio puede modificar la distribución hacia uno u otro sexo. Calculemos la ratio de masculinidad (RM) referida a los Censos de Población 


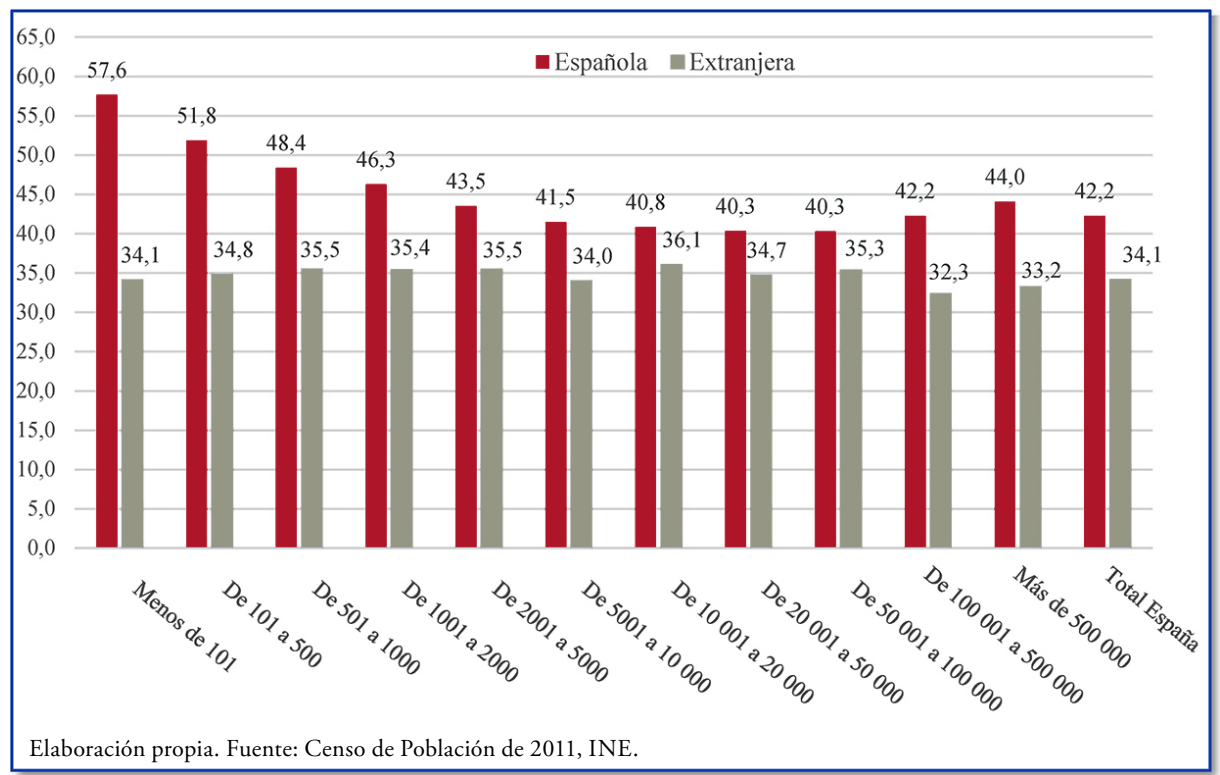

Gráfico 7. Edades medias de la población, ambos sexos, según nacionalidad en los municipios espańoles clasificados por tamaño demográfico en el Censo de Población de 2011.

de 1981 a 2011 y también al Padrón Continuo de 1 de enero de 2019 (datos definitivos) para los dos conjuntos municipales delimitados por el umbral de 5000 habitantes (ver gráfico 8). En 1981, la población de los municipios de hasta 5000 residentes concretizó un valor de 101,1 varones por cada 100 mujeres, mientras entre los municipios de más de 5000 habitantes fue de 95,4 por 100. En los siguientes Censos se manifestó repetidamente esa diferencia, pero con tendencia a crecer en los municipios de menos de 5001 residentes, definiendo en el último Censo de 2011 unas RM de 106 sobre 96,5 varones por 100 mujeres, respectivamente. En cuanto a la información estadística más actual, el Padrón Continuo de 1 de enero de 2019 nos informa que las RM concretizaron 105 hombres por cada 100 mujeres en los municipios de hasta 5000 residentes, reduciéndose a 95 varones por cada 100 mujeres en los que superaron ese tamaño. En resumen, el conjunto de los municipios de menos de 5001 habitantes muestra una clara masculinización de su población, un rasgo que se ha acentuado desde 1981.

En los municipios donde crece la ratio de masculinidad, generalmente se debe a un movimiento migratorio diferenciado por sexo: emigran más mujeres que hombres y/o inmigran más varones que mujeres. Las ocupaciones que dominan o escasean en los mercados locales y comarcales de trabajo determinan el sentido y género de los flujos migratorios en la población activa. En este sentido, si en el mercado de trabajo de los municipios y comarcas rurales faltan ocupaciones del sector 


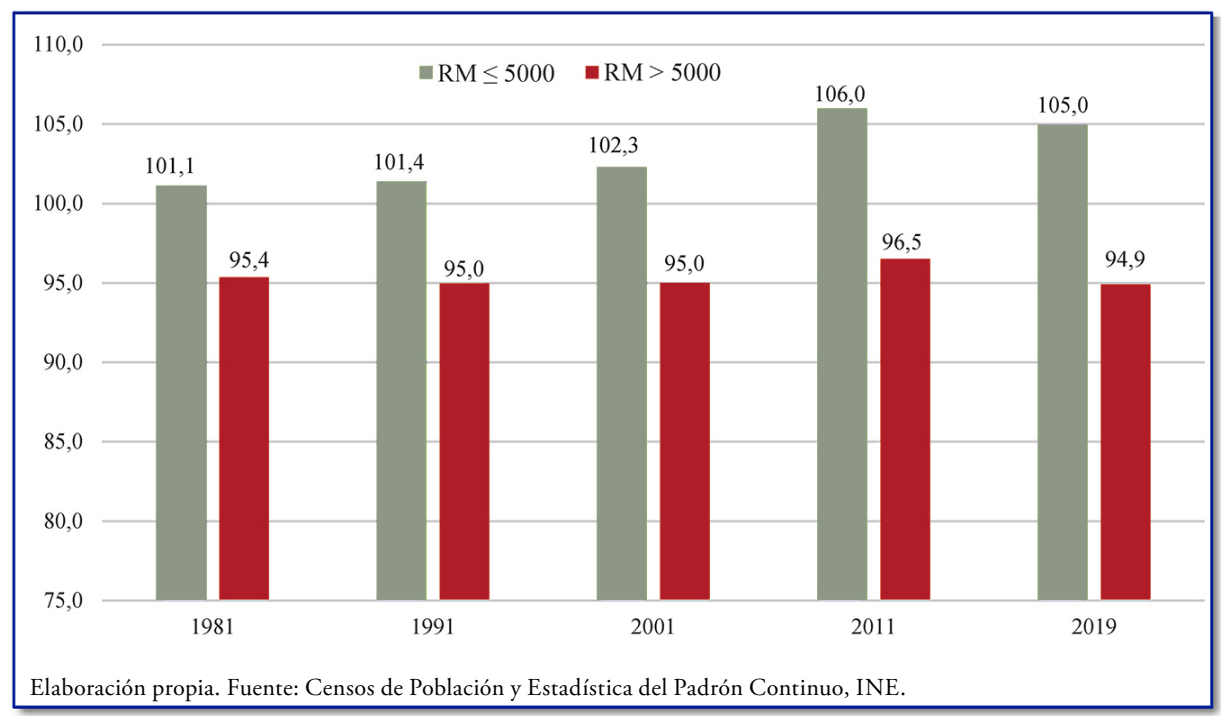

Gráfico 8. Ratios de masculinidad (hombres por cada 100 mujeres) en los municipios españoles de hasta 5000 y de más de 5000 habitantes en los Censos de Población de 1981, 1991, 2001 y 2011 y el Padrón Continuo de 2019 (datos definitivos).

terciario ${ }^{8}$, lo más probable será una corriente emigratoria de mujeres jóvenes y adultas activas hacia las urbes en busca de un empleo. Asimismo, si faltan ocupaciones de cualificación medio-alta en el mercado de trabajo local-comarcal, seguramente tendrá lugar una mayor emigración femenina, dado que su nivel de estudios suele ser más elevado con relación a los varones, una sobrecualificación femenina que sobre todo se manifiesta entre las jóvenes (Camarero y Sampedro, 2008).

Por lo general, la emigración femenina ha superado en cantidad a la masculina, implicando la masculinización de la estructura por sexo de la población en bastantes municipios rurales, contrarrestando la propensión a la feminización que suele derivar del proceso de envejecimiento en una población, motivada por la mayor longevidad de las mujeres. Al mismo tiempo, la inmigración extranjera ha contribuido a reforzar la masculinización de la población en el territorio rural, tal

${ }^{8}$ En el Censo de Población de 2011, el 58,4\% de la población ocupada de 16 y más años que residía en los municipios de hasta 5000 habitantes trabajaba en actividades del sector servicios, elevándose esta categoría al 76,2\% entre las y los ocupados de 16 y más años censados en los municipios que superaron los 5000 residentes. Entre las mujeres ocupadas de 16 y más años, el sector terciario significó el 77,3\% del total en los municipios de hasta 5000 habitantes, mientras este indicador se elevó al $87,5 \%$ entre las mujeres ocupadas de 16 y más años censadas en los municipios de más de 5000 residentes (fuente: Censo de Población de 2011, INE). 


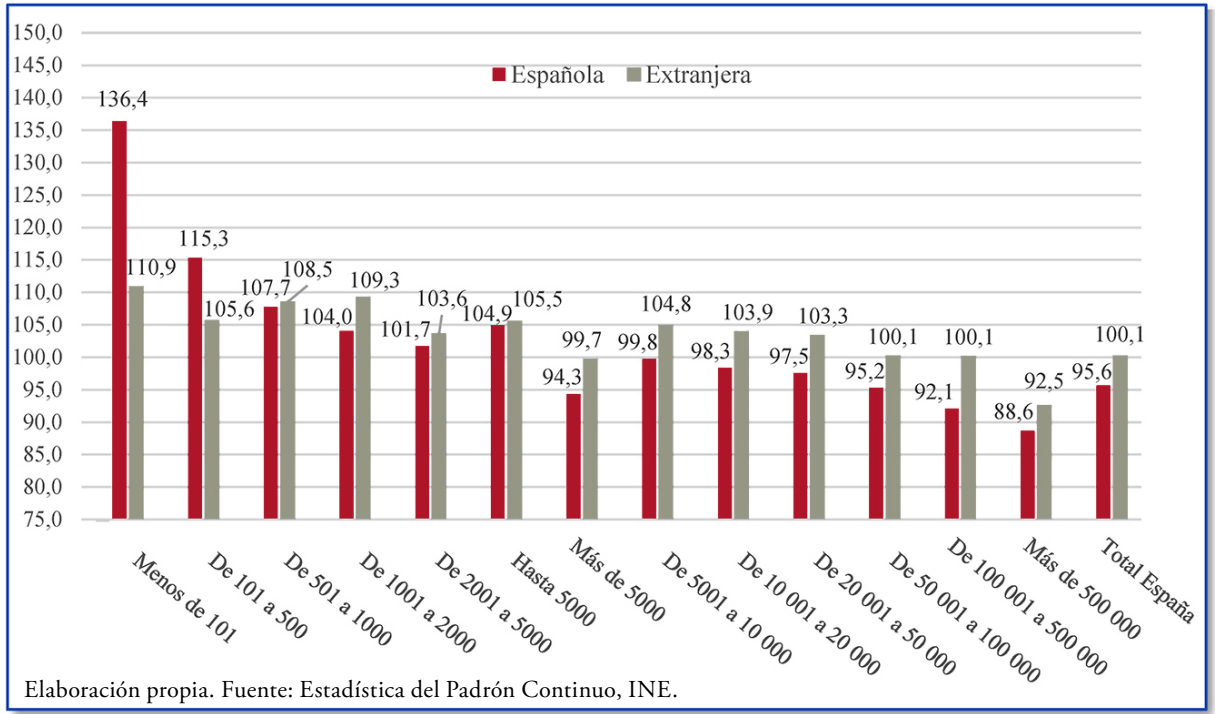

Gráfico 9. Ratios de masculinidad (hombres por cada 100 mujeres) según nacionalidad en los municipios españoles clasificados por tamaño demográfico en el Padrón Continuo de 1 de enero de 2019 (datos definitivos).

como se observa en el gráfico 9: según el Padrón Continuo de 1 de enero de 2019 (datos definitivos), la ratio de masculinidad entre las y los extranjeros empadronados en los municipios de hasta 5000 habitantes fue de 105,5 varones por cada 100 mujeres, cuando entre el colectivo de extranjeros empadronados en los municipios de más de 5000 vecinos la RM se redujo a 99,7 por 100. Más en concreto, en cada uno de los cinco estratos municipales con menos de 5001 habitantes, las RM de la población extranjera sobrepasaron el umbral de 100 (más varones que mujeres), y en los tres estratos de 501 hasta 5000 habitantes su valor se situó por encima de la RM de la población española.

\section{LA INMIGRACIÓN EXTRANJERA}

En general, los movimientos migratorios internacionales adquieren una gran importancia en el contexto de la Segunda Transición Demográfica, un marco conceptual propuesto por Ron Lesthaeghe y Dick van de Kaa (1987) para explicar los cambios sociodemográficos que observaron en las sociedades capitalistas posindustriales. Grosso modo, debido a la caída de la fecundidad y la natalidad, la población tiende a la estabilidad cuantitativa e incluso a decrecer (repunte de la mortalidad por el proceso de envejecimiento) en los países de capitalismo posindustrial, salvo que pasen a ser territorios receptores de los flujos migratorios internacionales. A partir 


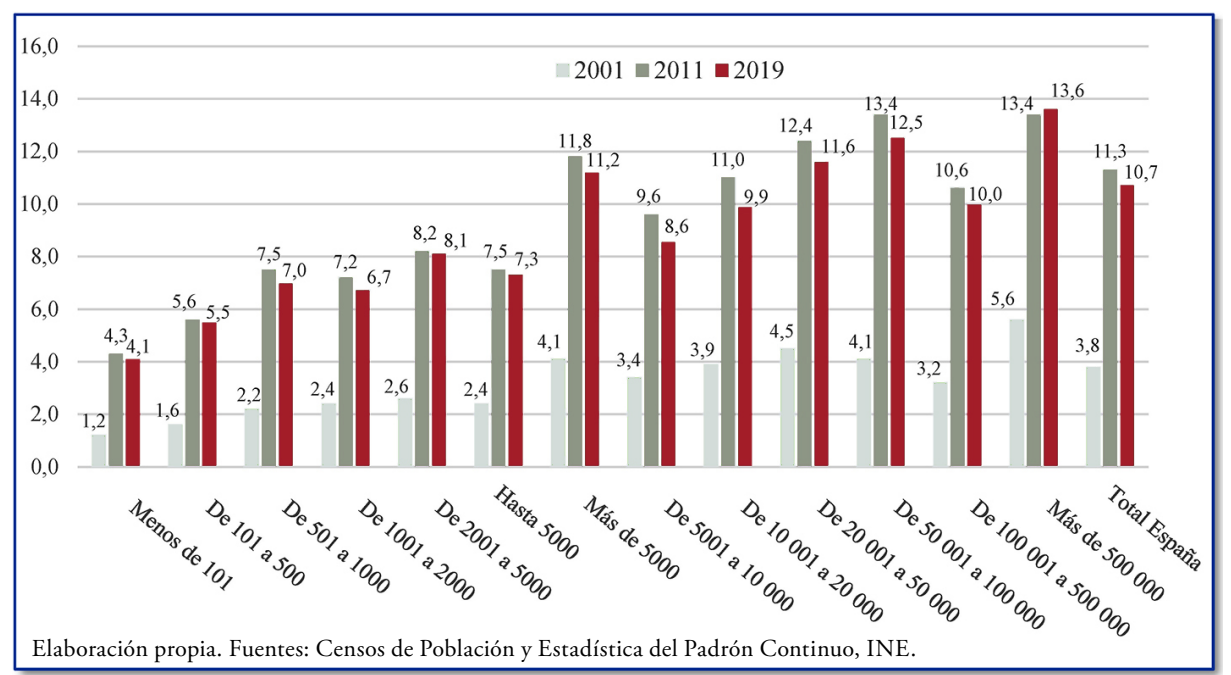

Gráfico 10. Porcentajes de población de nacionalidad extranjera, ambos sexos, en los Censos de Población de 2001 y 2011 y el Padrón Continuo de 2019 (datos definitivos) en los municipios espańoles clasificados por tamaño demográfico.

del último lustro del siglo xx, diversas áreas geográficas del Estado español comenzaron a recibir importantes flujos de inmigrantes extranjeros en busca de empleo y mejora de sus condiciones de vida, los cuales provocaron un cambio copernicano en los municipios donde se asentaron con cierta relevancia cuantitativa: la renovación y el rejuvenecimiento de la cohorte de personas activas y, en general, de la estructura por edad de la población, el aumento de la fecundidad y la natalidad, de la población infantil a escolarizar, etc. En este sentido, el declive demográfico de los municipios españoles de menos de 5001 habitantes hubiese sido aún mayor sin el aporte efectuado por la inmigración extranjera.

En el Censo de Población de 2001, las y los extranjeros censados en los municipios con hasta 5000 habitantes sumaron 147176 personas, que representaron el $2,4 \%$ de la población total residente en ese conjunto municipal. A 1 de enero de 2019 (datos definitivos), se contabilizó una cantidad de 416430 personas de nacionalidad extranjera, que significaron el 7,3\% de la población total empadronada en los municipios de hasta 5000 habitantes (ver gráfico 10). En general, entre noviembre de 2001 y enero de 2019, en los municipios de ese tamaño se manifestó una evolución muy positiva, pues el colectivo de residentes de nacionalidad extranjera creció nada menos que un $182,9 \%$, si bien con un incremento inferior con respecto al experimentado por los municipios que superaron los 5000 habitantes (224,3\%).

Por otro lado, la presencia relativa de la población extranjera en los municipios de hasta 5000 habitantes es inferior con respecto a la que alcanza entre los municipios que superan dicho tamaño: al iniciarse 2019, el 7,3\% frente al 11,2\% de 
la población empadronada en los municipios de más de 5000 habitantes. La asociación positiva entre el porcentaje de población extranjera y el tamaño del municipio se constata claramente, expresándose el mayor porcentaje de residentes extranjeros entre la población empadronada en los municipios de más de 500000 habitantes: $13,6 \%$ del total.

Generalmente, la integración social de los inmigrantes extranjeros en los municipios rurales ha sido un proceso complejo, salpicado de diversas barreras y dificultades, ante la preeminencia de valores y actitudes conservadoras entre la población rural, con una estructura por edad más envejecida. También hay que resaltar que no se ha producido una conflictividad generalizada, sino más bien bastante localizada en enclaves rurales especializados en la agricultura intensiva, condicionados por una importante concentración de trabajadores inmigrantes que laboran y sobreviven en condiciones de elevada explotación y precariedad, así como por una fuerte movilidad espacial (temporeros/as).

Por lo demás, el desempleo, la inestabilidad laboral, la pobreza más o menos severa, las dificultades materiales por las que ha pasado la formación social española debido a la última crisis capitalista de 2008 a 2013 han incidido negativamente en la permanencia de las personas y familias extranjeras en los municipios rurales. En este sentido, la denominada Gran Recesión disminuyó el colectivo de residentes extranjeros, cuya cantidad no se ha recuperado con suficiencia durante la nueva etapa de crecimiento económico: en el conjunto de los municipios de hasta 5000 habitantes se registró un decremento de -6,8\% entre el Censo de Población de noviembre de 2011 y el Padrón Continuo de enero de 2019 (datos definitivos). En todo caso, buena parte de las y los inmigrantes extranjeros han optado por permanecer en los municipios rurales, lo que revaloriza su potencialidad para contribuir al rejuvenecimiento de la población activa y sostenibilidad demográfica de los municipios rurales, parte de los cuales, sin su beneficiosa aportación, estarían abocados irremediablemente al abandono. No obstante, las oportunidades de empleo a las que pueden acceder, con frecuencia sujetas a la precariedad y explotación laboral, y las dificultades/facilidades para crear y desarrollar sus proyectos familiares, incluyendo la accesibilidad a una vivienda asequible y habitable, condicionarán su arraigo y permanencia o movilidad espacial (Camarero y Sampedro, 2016).

\section{LAS PIRÁMIDES DE POBLACIÓN}

A continuación, vamos a representar gráficamente la estructura por sexo y edad de la población del conjunto de municipios de hasta 5000 habitantes mediante la figura de una pirámide, que trazaremos para los datos del Censo de Población de 1991 y del Padrón Continuo de 1 de enero de 2019 (datos definitivos). En el gráfico 11, al comparar la pirámide de población de 2019 con la respectiva de 1991, observamos con claridad en los dos sexos una significativa contracción en los histogramas correspondientes a las cohortes de la infancia ( 0 a 14 años) y la juventud (15 a 34 años), así como una dilatación bastante pronunciada en los histogramas de las cohortes de la adultez (35 a 49 años) y madurez (50 a 59 años). Con relación al 


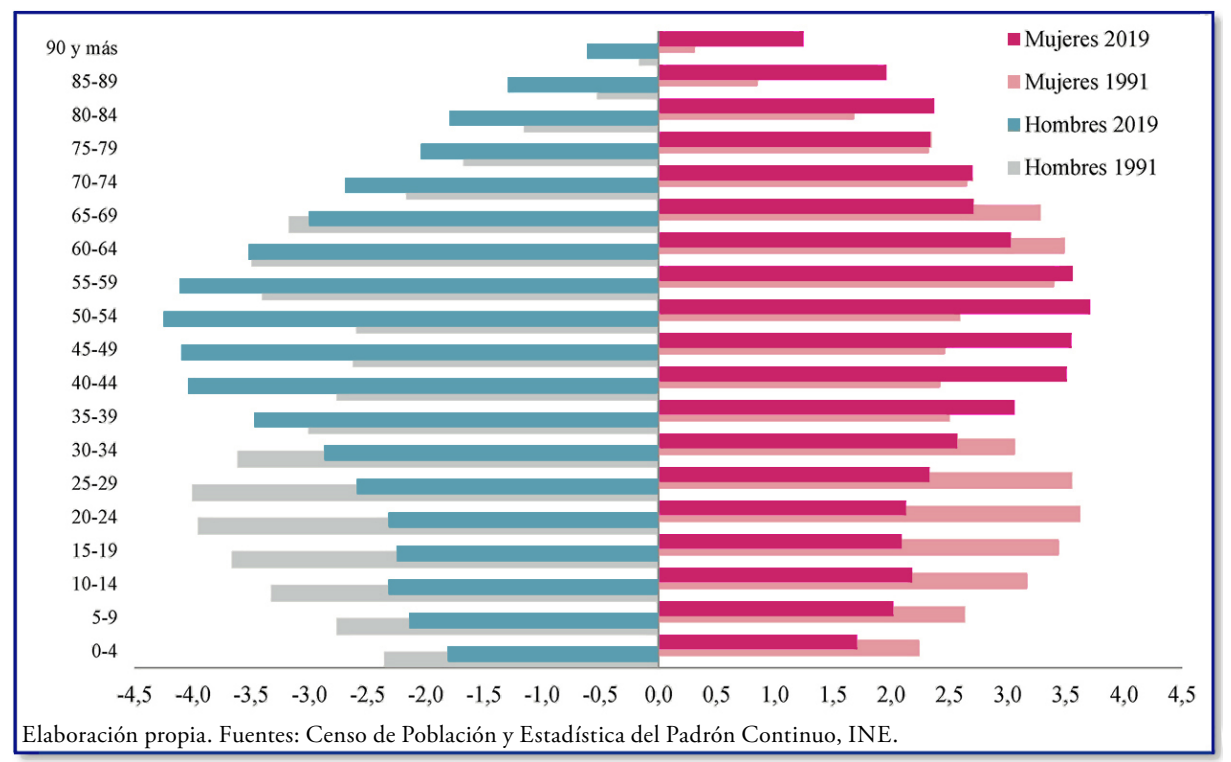

Gráfico 11. Pirámides de población de los municipios de hasta 5000 habitantes en el Censo de Población de 1991 y el Padrón Continuo de 2019 (datos definitivos).

área de la cúspide de la pirámide se advierte que en los varones (izquierda) los histogramas se expanden a partir de 70-74 años, mientras entre las mujeres la dilatación es algo más tardía, a partir de 80-84 años.

Si en el Censo de Población de 1991, la estructura por sexo y edad de la población de los municipios de hasta 5000 habitantes ya se mostraba envejecida (19,2\% de efectivos de 65 y más años) y moderadamente masculinizada (101,4 varones por cada 100 mujeres), en el Padrón Continuo de 1 de enero de 2019 ambos rasgos demográficos se han acrecentado (24,8\% y 104,9, respectivamente). Más en concreto, la pirámide de población de los municipios de hasta 5000 habitantes en 2019 refleja una estructura por edad con preeminencia de las cohortes de la madurez $(22,2 \%)$ y vejez $(24,8 \%)$, con una presencia relevante de la 'cuarta edad' (9,3\% de personas de 80 y más años). La masculinización de la estructura por sexo comienza a manifestarse con claridad en la cohorte de la juventud (109,9 varones por cada 100 mujeres), acentuándose a continuación en las cohortes de la adultez $(114,6)$ y madurez $(115,3)$, mientras en la vejez la mayor longevidad femenina determina una mayoría de mujeres (85,8 hombres por cada 100 mujeres).

Por otro lado, en el gráfico 12 recogemos las pirámides de población para los conjuntos municipales de hasta 5000 y de más de 5000 habitantes según el Padrón Continuo de 1 de enero de 2019 (datos definitivos). A derecha (mujeres) e izquierda (hombres) de la pirámide para los municipios de menos de 5001 residentes se observa una mayor concavidad en los histogramas de la infancia (0 a 14 


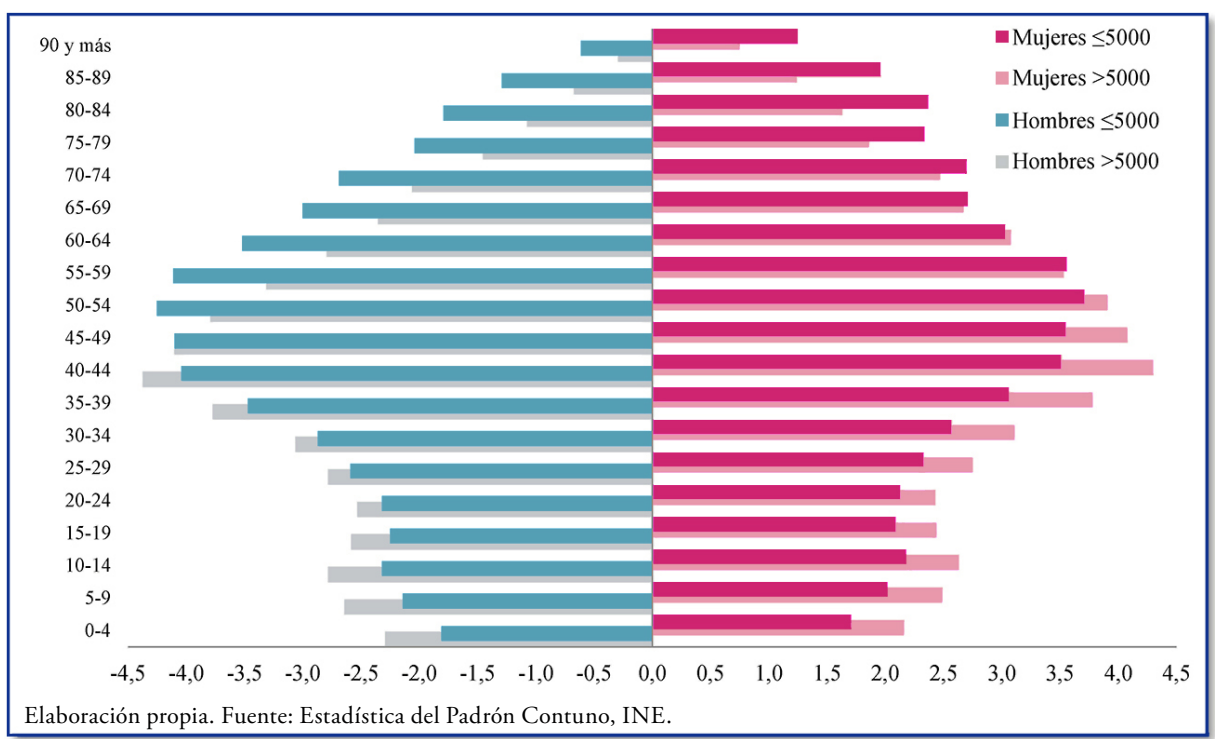

Gráfico 12. Pirámides de población de los municipios de hasta 5000 y de más 5000 habitantes en el Padrón Continuo de 2019 (datos definitivos).

años), juventud (15 a 34 ańos) y adultez (35 a 44 años). Por el contrario, a partir del grupo de 50-54 años en los varones y de 60-64 años en las mujeres se percibe una mayor longitud en los histogramas de la pirámide de población de los municipios de hasta 5000 habitantes. Ambos rasgos -contracción en los histogramas de la base y dilatación en los de la cúspide piramidal- son característicos de una población más afectada por el proceso de envejecimiento. Por último, queremos señalar que en la cohorte de 35 a 64 años, en la que se concentra la población activa, se observa una amplitud mayor de los histogramas de los varones que de las mujeres entre la población del conjunto de los municipios de hasta 5000 habitantes, seguramente por la mayor emigración femenina.

\section{UN DESIERTO DEMOGRÁFICO}

Aparte del sobreenvejecimiento y la masculinización de la población, la consecuencia más grave del proceso persistente de despoblación y abandono que sufre el medio rural consiste en la 'desertización humana' del territorio. Si indagamos sobre el grado de despoblación y abandono mediante el indicador de la densidad municipal de población (ver tabla II), conocemos que los municipios de hasta 100 habitantes solamente tienen una densidad media de 2,3 habitantes por $\mathrm{km}^{2}$ y los de 101 a 500 habitantes de 6 residentes por $\mathrm{km}^{2}$ con referencia temporal al Padrón Con- 
tinuo de 1 de enero de 2019 (datos definitivos). Observamos que ambos estratos municipales tienen densidades medias inferiores a 10 habitantes por $\mathrm{km}^{2}$, el nivel de poblamiento de un territorio que en sociología de la población y rural consideramos propio de un 'desierto demográfico'. Además, el siguiente estrato municipal de 501 a 1000 habitantes define una densidad media de 11,6 residentes por $\mathrm{km}^{2}$, muy cercana a esa frontera que da paso al desierto demográfico, donde seguramente se situará este estrato municipal en una próxima revisión anual del Padrón Continuo.

\begin{tabular}{|c|c|c|c|c|}
\hline \multicolumn{5}{|c|}{$\begin{array}{c}\text { TABLA II. DENSIDAD DE POBLACIÓN PARA LOS ESTRATOS MUNICIPALES SEGÚN } \\
\text { TAMAÑO DEMOGRÁFICO A } 1 \text { DE ENERO DE } 2019 \text { (DATOS DEFINITIVOS): } \\
\text { NÚMERO DE HABITANTES POR KM }{ }^{2}\end{array}$} \\
\hline ESTRATOS MUNICIPALES & $\begin{array}{c}\text { N.o } \\
\text { Municipios }\end{array}$ & Población & $\begin{array}{c}\text { Superficie } \\
\mathrm{KM}^{2}\end{array}$ & $\begin{array}{l}\text { DENSIDAD DE } \\
\text { POBLACIÓN: } \\
\text { HABS. POR KM }\end{array}$ \\
\hline Menos de 101 habitantes & 1352 & 76828 & 33728,94 & 2,28 \\
\hline De 101 a 500 habitantes & 2645 & 658384 & 110383,04 & 5,96 \\
\hline De 501 a 1000 habitantes & 1003 & 721203 & 62096,79 & 11,61 \\
\hline De 1001 a 2000 habitantes & 877 & 1242862 & 70055,91 & 17,74 \\
\hline De 2001 a 5000 habitantes & 952 & 300351 & 80448,79 & 37,30 \\
\hline Hasta 5000 habitantes & 6829 & 5699628 & 356713 & 15,98 \\
\hline Más de 5000 habitantes & 1302 & 41326580 & 148031 & 279,17 \\
\hline De 5001 a 10000 habitantes & 549 & 3865826 & 51625,70 & 74,88 \\
\hline De 10001 a 20000 habitantes & 340 & 4787781 & 32363,61 & 147,94 \\
\hline De 20001 a 50000 habitantes & 265 & 7765329 & 35875,27 & 216,45 \\
\hline De 50001 a 100000 habitantes & 85 & 6075765 & 14223,65 & 427,16 \\
\hline De 100001 a 500000 habitantes & 57 & 11196460 & 11587,92 & 966,22 \\
\hline Más de 500000 habitantes & 6 & 7635419 & 2355,19 & 3241,96 \\
\hline ESPAÑA & 8131 & 47026208 & 504744,80 & 93,17 \\
\hline
\end{tabular}

Elaboración propia. Fuentes: Estadística del Padrón Continuo de 01/01/2019 (datos definitivos) del Instituto Nacional de Estadística (INE) y Nomenclátor Geográfico de Municipios y Entidades de Población del Instituto Geográfico Nacional (IGN).

Resaltar que, a 1 de enero de 2019, en 3530 municipios el valor de este indicador no logró superar los 10 habitantes por $\mathrm{km}^{2}$. Con respecto al total de municipios españoles (8131), representan nada menos que el $43,4 \%$ de todos ellos y, en cuanto a la superficie de España, abarcan el 43,2\% del territorio estatal, sumando una población de 997359 habitantes, que tan solo significa el 2,1\% del total espańol, con una densidad promedio para este conjunto municipal de 4,6 residentes por $\mathrm{km}^{2}$. Dentro de esta categoría de municipios donde los seres humanos escasean, 2153 términos (26,5\% de todos los municipios españoles) destacan por acoger menos de 5 habitantes por $\mathrm{km}^{2}$, los cuales albergan en conjunto una población de 366717 personas ( $0,8 \%$ del total español), que se dispersan por un cuarto $(25,9 \%)$ del territorio estatal y representan una densidad media de 2,8 habitantes por $\mathrm{km}^{2}$. 
A continuación, atendamos a la distribución de los municipios con menos de 10 habitantes por $\mathrm{km}^{2}$ entre las 17 comunidades autónomas (ver tabla III): al iniciarse 2019, se observa que casi la mitad se concentran en Castilla y León (1582 términos que significan el 44,8\% del total estatal), despuntando en segundo lugar, pero a cierta distancia, Castilla-La Mancha (582 que representan el 16,5\%) y Aragón (522 que simbolizan el 14,8\%). Las tres comunidades autónomas suman el 76,1\% del total de municipios españoles con menos de 10 habitantes por $\mathrm{km}^{2}$, los cuales representan un nivel de poblamiento propio de un desierto demográfico.

\begin{tabular}{|c|c|c|c|c|c|c|}
\hline \multicolumn{7}{|c|}{$\begin{array}{l}\text { TABLA III. DISTRIBUCIÓN POR COMUNIDADES AUTÓNOMAS DE LOS MUNICIPIOS } \\
\text { CON UNA DENSIDAD DE POBLACIÓN INFERIOR A } 10 \text { HABITANTES POR KM² } \\
\text { A } 1 \text { DE ENERO DE } 2019 \text { (DATOS DEFINITIVOS) }\end{array}$} \\
\hline $\begin{array}{l}\text { COMUNIDADES } \\
\text { AUTÓNOMAS }\end{array}$ & $\begin{array}{c}\text { (A) N. }{ }^{\circ} \\
\text { MUNICIPIOS }\end{array}$ & $\begin{array}{l}\% \text { (A) SOBRE TOTAL } \\
\text { MUNICIPIOS DE } \\
\text { C. AUTÓNOMA }\end{array}$ & $\begin{array}{c}\% \text { (A) SOBRE TOTAL } \\
\text { MUNICIPIOS } \\
<10 \text { HAB. POR KM }{ }^{2}\end{array}$ & Población & $\begin{array}{l}\text { SUPERfiCIE } \\
\mathrm{KM}^{2}\end{array}$ & $\begin{array}{l}\text { DENSIDAD } \\
\text { MEDIA DE } \\
\text { POBLACIÓN: } \\
\text { HABS. POR KM }{ }^{2}\end{array}$ \\
\hline Andalucía & 117 & 14,90 & 3,31 & 120885 & 19091,32 & 6,33 \\
\hline Aragón & 522 & 71,41 & 14,79 & 120422 & 32490,05 & 3,71 \\
\hline Asturias & 22 & 28,21 & 0,62 & 19394 & 3354,88 & 5,78 \\
\hline Balears (Illes) & 1 & 1,49 & 0,03 & 212 & 139,39 & 1,52 \\
\hline Canarias & 1 & 1,14 & 0,03 & 758 & 103,71 & 7,31 \\
\hline Cantabria & 26 & 25,49 & 0,74 & 14061 & 2389,34 & 5,88 \\
\hline Castilla y León & 1582 & 70,37 & 44,82 & 283636 & 65754,98 & 4,31 \\
\hline Castilla-La Mancha & 582 & 63,33 & 16,49 & 186524 & 46453,22 & 4,02 \\
\hline Cataluña/Catalunya & 205 & 21,65 & 5,81 & 55405 & 11940,53 & 4,64 \\
\hline C. Valenciana & 93 & 17,16 & 2,63 & 31746 & 6120,47 & 5,19 \\
\hline Extremadura & 142 & 36,60 & 4,02 & 93570 & 16958,53 & 5,52 \\
\hline Galicia/Galiza & 27 & 8,63 & 0,76 & 27760 & 4363,55 & 6,36 \\
\hline Madrid & 19 & 10,61 & 0,54 & 3236 & 541,10 & 5,98 \\
\hline Murcia & 1 & 2,22 & 0,03 & 7839 & 952,61 & 8,23 \\
\hline Navarra/Nafarroa & 90 & 33,09 & 2,55 & 16641 & 3779,27 & 4,40 \\
\hline País Vasco/Euskadi & 13 & 5,18 & 0,37 & 6163 & 1088,93 & 5,66 \\
\hline La Rioja & 87 & 50,00 & 2,46 & 9107 & 2678,51 & 3,40 \\
\hline ESPAÑA & 3530 & 43,41 & 100,00 & 997359 & 218200,39 & 4,57 \\
\hline
\end{tabular}

Elaboración propia. Fuentes: Estadística del Padrón Continuo de 01/01/2019 (datos definitivos), Instituto Nacional de Estadística (INE) y Nomenclátor Geográfico de Municipios y Entidades de Población del Instituto Geográfico Nacional (IGN).

En el mapa 1, recogemos las comunidades autónomas según el porcentaje de municipios con menos de 10 habitantes por $\mathrm{km}^{2}$ a 1 de enero de 2019 y observamos que, en cuatro autonomías, este tipo de municipios representan por lo menos la mitad de sus términos municipales: La Rioja (50,0\%), Castilla-La Mancha (63,3\%), Castilla y León $(70,4 \%)$ y Aragón $(71,4 \%)$. Además, con alrededor de un tercio de 


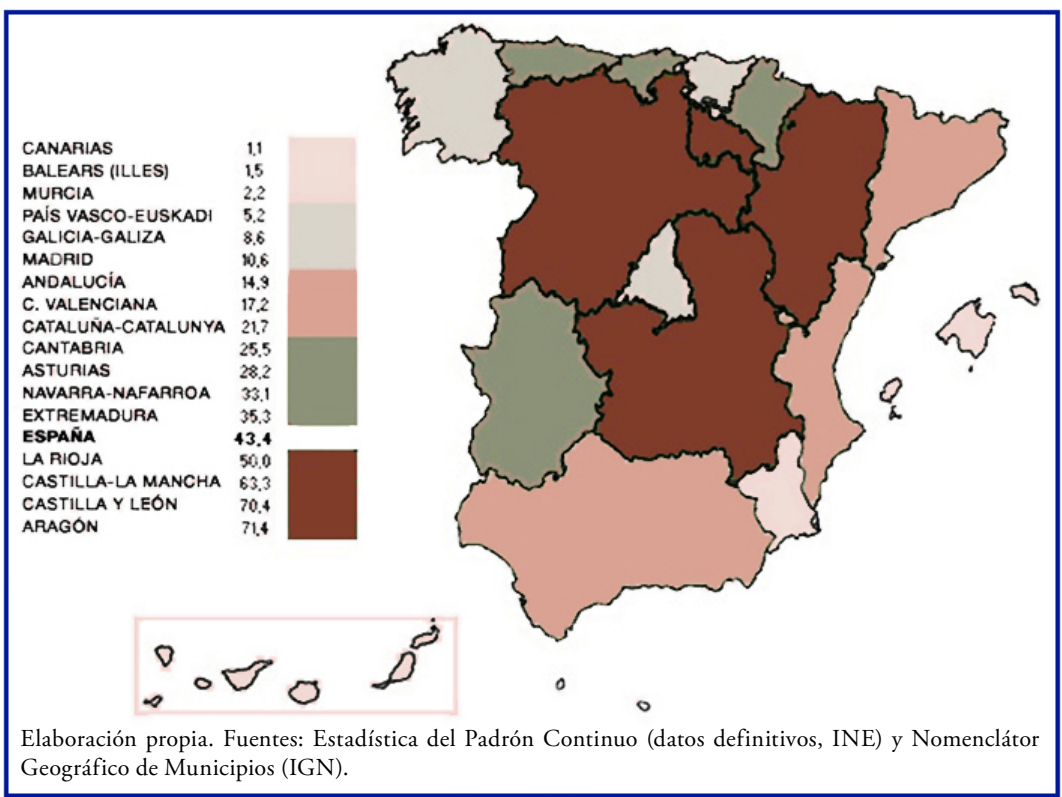

Mapa 1. Comunidades autónomas según el porcentaje de municipios con menos de 10 habitantes por $\mathrm{km}^{2}$ sobre total de municipios de la C.A. en el Padrón Continuo de 01/01/2019.

sus municipios con esa baja densidad demográfica, propia de un 'desierto humano', aparecen otras dos comunidades: Navarra $(33,1 \%)$ y Extremadura (36,6\%). En resumen, la problemática de la desertización demográfica del territorio rural afecta principalmente a las comunidades autónomas del interior peninsular, en las cuales se concentra la 'España vacía' (Del Molino, 2016), que nosotros preferimos denominar 'vaciada', en la medida en que las políticas y actuaciones públicas y privadas han promovido, directa o indirectamente, su despoblación y abandono.

\section{CONCLUSIONES}

La mayoría del territorio rural del interior peninsular está atrapado en un proceso de despoblación y abandono, con consecuencias de sobreenvejecimiento y creciente masculinización de su estructura por edad y sexo, como ejemplifican los indicadores demográficos que hemos analizado para los cinco estratos en los que el INE clasifica estadísticamente los municipios de hasta 5000 habitantes. Así, entre 2000 y 2019 , este conjunto de municipios perdió el $8 \%$ de sus residentes y su índice de envejecimiento aumentó desde 184,3 hasta 203,3 mayores de 64 años por cada cien menores de 15 años, lo que nos permite afirmar que la estructura por edad de los municipios de hasta 5000 habitantes, más que envejecida, está sobreenvejecida, pues uno de cada cuatro habitantes tiene más de 64 años. 
En cuanto a la estructura por sexo, la ratio de masculinidad nos manifiesta que durante las dos primeras décadas del siglo Xxi ha proseguido afianzándose el fenómeno demográfico de la masculinización de la población residente, ya que su valor aumentó desde 102,3 hasta 105 varones por cada cien mujeres en los municipios de hasta 5000 habitantes. La masculinización de la población rural nos advierte de una emigración más numerosa entre las mujeres activas, en su mayoría de la cohorte con potencialidad reproductiva ( 15 a 49 años), constituyendo uno de los principales talones de Aquiles, si no es el fundamental, para la renovación y la misma supervivencia del poblamiento rural que está alejado de las ciudades y no ha conseguido insertarse en las redes económicas de la globalización capitalista (Trabada et al., 2007; Trabada, 2019).

En este escenario rural de demografía regresiva, a contracorriente destaca el aumento de la población de nacionalidad extranjera: si en el Censo de Población de 2001 solo significaron el 2,4\% de la población total de los municipios de hasta 5000 habitantes, en la revisión del Padrón Continuo de 2019 su importancia se elevó al 7,3\%. Por consiguiente, resalta como el colectivo demográfico que ha moderado las pautas de despoblación y sobreenvejecimiento que dominan en la mayoría de los municipios rurales, aunque con respecto a la masculinización de la población rural ha contribuido a potenciarla (105,5 varones por cada 100 mujeres de nacionalidad extranjera).

Con relación a la desertización humana del territorio, al comenzar el año 2019 se contabilizan 3530 municipios cuya densidad de población no consiguió superar el umbral de los 10 habitantes por $\mathrm{km}^{2}$, los cuales significan el $43,4 \%$ del total de municipios españoles y, por término medio, tienen una densidad de 4,6 residentes por $\mathrm{km}^{2}$. Este grupo de municipios escasamente poblados se concentran en las comunidades autónomas del interior peninsular, resaltando Castilla-La Mancha (63,3\%), Castilla y León $(70,4 \%)$ y Aragón $(71,4 \%)$, ya que más de la mitad de sus términos municipales tienen menos de 10 habitantes por $\mathrm{km}^{2}$.

En resumidas cuentas, el declive de población, el sobreenvejecimiento de la estructura por edad, la masculinización de la estructura por sexo y la desertización demográfica del territorio conforman un escenario de profunda crisis demográfica y, dada la estrecha relación que se establece entre población, economía, sociedad y Administración local en el medio rural, seguramente implicará que proseguirá agravándose en los municipios rurales segregados, cuando no excluidos, de las redes y actividades económicas del capitalismo globalizado, tal como ha sucedido durante el tiempo transcurrido del siglo XXI.

La crisis demográfica contribuye a la crisis de la economía local, y el entrelazamiento de ambas promueve la crisis institucional y social en el territorio rural. Las relaciones negativas de retroalimentación o feed-back (causa $\leftrightarrows$ efecto) entre estas crisis conforman una crisis estructural de 'círculo vicioso' (ver cuadro 1) que impulsa la creciente desinversión y posterior cierre de explotaciones agrarias, de empresas y negocios por falta de 'masa crítica' (relevo generacional, mano de obra, consumidores), así como la pérdida del capital invertido y el abandono de instalaciones y medios de producción, como ya sucede en los municipios de la 'España vaciada'. 


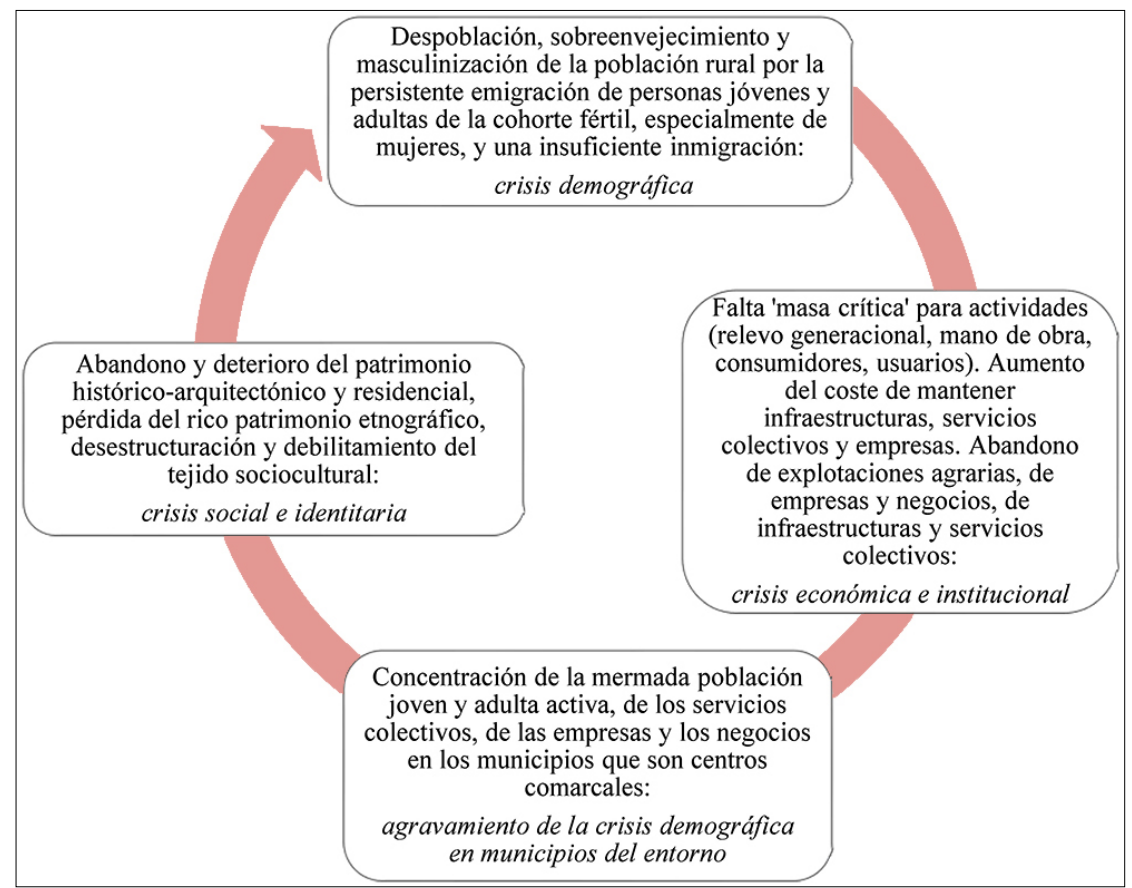

Elaboración propia. Fuente: Trabada, E. (2019).

A la par, se produce una concentración de la mermada población activa joven y adulta con hijos en los municipios rurales que son centros comarcales, en los cuales se centralizan los servicios colectivos básicos (centro de salud de especialidades y urgencias, farmacias, centros de educación obligatoria, oficinas agrarias autonómicas, oficinas bancarias, gestorías, comercios, talleres de reparación, restauración y ocio, etc.), exacerbando la crisis demográfica en los municipios de su área de influencia. Por lo demás, la mayoría del personal técnico y cualificado ocupado en los servicios colectivos públicos y privados no suelen residir en los municipios rurales en los que trabajan diariamente, pues prefieren alojarse con sus familias en la capital provincial o, si está muy distante, en el municipio que actúa como cabecera comarcal en su zona de trabajo.

El encadenamiento de las crisis demográfica y económica siembra una crisis institucional que se manifiesta en el abandono y deterioro de infraestructuras públicas y el cierre de equipamientos colectivos, tanto públicos como privados, necesarios para la vida cotidiana de las y los ruralitas. Otro tanto sucede con el patrimonio residencial e histórico-arquitectónico, con la pérdida del rico y heterogéneo patrimonio etnográfico del mundo rural, junto con la creciente desestructuración y debilitamiento de su tejido sociocultural (redes y grupos animadores 
de la vida local), derivando en una crisis social e identitaria profunda, que genera anomia y desarraigo intenso entre las y los ruralitas. En resumen, vuelta de tuerca tras vuelta de tuerca, la concatenación y retroalimentación de las crisis demográfica, económica, institucional y social se va imponiendo como un escenario de crisis estructural irreversible, que conlleva necesariamente la desertización humana del territorio rural afectado.

\section{ALGUNAS RECOMENDACIONES}

El territorio rural que se distingue por la escasez de seres humanos nos remite a una realidad local muy condicionada por carencias y desatenciones absolutas, en cuanto a las necesidades y demandas básicas de la población rural, así como por sobrecostes e ineficacias crecientes en la gobernanza municipal, las cuales determinan un modelo atomizado y minifundista de Administración local, que gestiona como puede y cuando puede un extenso y abandonado medio rural, una situación frecuente en el interior peninsular. Urge, pues, una reforma política de la Administración local, pero en la que domine una lógica democrática ascendente (de abajo hacia arriba) en vez de despótica descendente (de arriba hacia abajo) respecto de la gobernanza, ordenación y planificación del territorio que necesita la sociedad rural que ya es un desierto demográfico o parece destinada irreversiblemente a serlo. En este sentido, la reforma político-administrativa que apuntamos debería centrarse en la construcción democrática de instituciones intermunicipales (mancomunidades o comarcas), que surjan de la asociación federativa de municipios -en vez de crearse por imposición legal-, las cuales deberán disponer de suficiente presupuesto y capacidad técnico-burocrática, además del apoyo de la Administración autonómica, para dar los servicios necesarios a las y los ruralitas en su ámbito territorial.

En esta reforma político-administrativa tan necesaria para el presente y el futuro de nuestro territorio rural, se debería debatir y consensuar entre los actores sociales, económicos y políticos - con principal protagonismo de los rurales-sobre qué hacer con las treinta y ocho diputaciones provinciales existentes ${ }^{9}$. En principio, hay dos opciones a considerar: o se mantienen, pero reformándolas en profundidad, o se suprimen y sustituyen por instituciones de ámbito comarcal. Pensamos que es necesaria la existencia de una organización pública supramunicipal entre las administraciones municipales y autonómicas, especialmente en las comunidades pluriprovinciales. Tras un proceso constituyente comarcal, basado en municipios veci-

9 No nos referimos a las tres diputaciones forales de la C.A. de Euskadi, los siete cabildos insulares de la C.A. de Canarias y los cuatro consells isulars de la C.A. Illes Balears, unas instituciones de la Administración local del Estado español cuyos miembros son elegidos por sufragio directo y que disfrutan de una especial protección jurídica, cuya supresión implicaría una reforma de la Constitución española de 1978. A diferencia de las 38 diputaciones provinciales de régimen común, cuya supresión no exigiría una reforma constitucional. 
nos que se federan en $\operatorname{comarcas}^{10}$, estas instituciones podrían cumplir con eficacia y eficiencia con ese rol de gobierno y Administración intermedia, pero, a su vez, la Administración autonómica deberá asumir infraestructuras provinciales, como el mantenimiento de la red viaria, y apoyar económica y técnicamente a las comarcas en aquellos servicios colectivos que requieran de su colaboración o impliquen a dos o más comarcas vecinas. En este nuevo escenario, las diputaciones provinciales serían reemplazadas gradualmente por las comarcas y una parte de su burocracia pasará a formar parte de las nuevas administraciones comarcales y el resto se integraría en las delegaciones autonómicas provinciales.

Somos conscientes de que no hay soluciones que, a modo de panaceas, puedan modificar sustancialmente el escenario rural de crisis demográfica y estructural que hemos descripto anteriormente. Pero tampoco nuestros pueblos y municipios rurales han de ser abocados y abandonados, como si fuese su destino inexorable, a la despoblación continuada y al vaciamiento total, como si todos ellos tuviesen que repetir maquinalmente la historia de Ainielle, la localidad oscense deshabitada recreada por Julio Llamazares en su novela La lluvia amarilla (1988).

Apreciamos que es urgente un 'cambio copernicano' en las políticas de ordenación y planificación territorial, diseñando e implementando democráticamente unas políticas alternativas que -promovidas desde abajo hacia arriba por la sociedad rural, mediante el empoderamiento de las y los ruralitas y sus asociaciones- posibiliten una reordenación y requilibrio entre los territorios rural y urbano en el Estado español. Unas políticas alternativas que pretendan superar el modelo neocolonialista que domina actualmente en las relaciones entre el campo y la ciudad, que tanto perjudican al primer tipo de hábitat. Que frente al productivismo, la hipercompetitividad, hiperespecialización e hiperflexibilidad que imponen los actores capitalistas dominantes en los mercados nacionales y mundiales, se prime la calidad y la sostenibilidad ambiental, la convivencialidad ${ }^{11}$, la economía social y el buen vivir de los pobladores humanos y el bienestar de los otros animales, así como la biodiversidad en el ecosistema rural.

Existen alternativas posibles que sí pueden desencadenar cambios socioeconómicos positivos de cierta magnitud, mediante las cuales se implementen nuevas tendencias y procesos de renovación, recualificación, reequilibrio y cohesión socioterritorial, que posibiliten la supervivencia de una parte relevante de los municipios rurales actualmente inmersos en una grave crisis demográfica que amenaza su exis-

${ }^{10}$ Una mancomunidad creada para mejorar el abastecimiento de agua o la recogida y tratamiento de residuos entre varios municipios puede ser una excelente base institucional desde la que promover la constitución democrática y federal de una comarca entre esos y otros municipios vecinos.

11 Para Iván Illich: «Una sociedad convivencial es la que ofrece al hombre la posibilidad de ejercer la acción más autónoma y más creativa, con ayuda de las herramientas menos controlables por los otros. La productividad se conjuga en términos de tener, la convivencialidad en términos de ser. En tanto que el incremento de la instrumentación, pasados los umbrales críticos, produce siempre más uniformación reglamentada, mayor dependencia, explotación e impotencia, el respeto a los límites garantizará un libre florecimiento de la autonomía y de la creatividad humanas» (Illich, 1985: 20). 
tencia. Pensamos que las políticas alternativas pasan, necesariamente, por promover un ecodesarrollo endógeno e integral que supere los artificiales divorcios y contradicciones entre ecología, economía y sociedad (Naredo, 2006). Así, en cada una de las comarcas rurales que surjan de la federación de municipios vecinos se debería diseñar y planificar un plan comarcal de ecodesarrollo endógeno e integral (Vázquez, 2007), basándose en una metodología integrada e intersectorial, participativa y bidireccional (ascendente $\leftrightarrows$ descendente), que promueva 'conjuntos de acción' comarcales (Rodríguez-Villasante, 2009), con la suficiente transversalidad, cooperación y coordinación entre los diferentes actores, instituciones y sectores implicados (Izquierdo, 2002).

A través de los planes comarcales se debería poner en marcha un proceso de transición ecológica mediante la progresiva desintensificación de las explotaciones agrarias, que incluya el fomento de la agroecología (Sevilla, 2006), pero también de formas híbridas o mixtas como la ganadería y agricultura familiar semiintensiva o semiextensiva con una doble finalidad: a) potenciar la sostenibilidad ambiental y la circularidad de la economía agraria comarcal, y b) frenar la despoblación generada por el proceso de concentración-intensificación de las actividades agropecuarias en explotaciones de mayor tamaño, capital y tecnificación, las cuales emplean menos fuerza de trabajo y alimentan el declive demográfico (Trabada, 2019). Asimismo, hay que promover la transformación y comercialización directa de los productos agroecológicos y de calidad diferenciada a través de microempresas de la misma comarca, dando prioridad a la economía social para superar la tragedia de los comunes $^{12}$, lo que contribuirá a fijar mujeres de la cohorte fértil, personas jóvenes y adultas con estudios superiores, renovando la sobreenvejecida y declinante población activa (Trabada, 2020).

Por otro lado, la crisis sociosanitaria provocada por el covid-19 y las medidas de confinamiento y restricción de la movilidad de la población aprobadas por los gobiernos estatal y autonómicos han generado una oportunidad factible para el

12 Con la tragedia de los comunes, no solo nos referimos al dilema que surge en el aprovechamiento de los recursos y bienes comunes entre la lógica del interés individual que pretende maximizar el beneficio particular y la lógica del interés colectivo que pretende, mediante la coerción-regulación, un aprovechamiento sostenible de esos mismos recursos y bienes más allá del corto plazo, como teorizó el biólogo y demógrafo Garret Hardin (2005). También queremos aludir al dilema socioeconómico que se plantea en las explotaciones familiares respecto de competir o cooperar entre ellas para mejorar su estrategia de sobrevivencia, eficacia y calidad de vida. En la regulación neoliberal y la PAC se prioriza la competitividad, productividad, eficiencia y rentabilidad de las explotaciones familiares, una lógica económica que ha conducido a la competencia entre las explotaciones familiares y al cierre y abandono de las que han sido incapaces de continuar en esa loca carrera capitalista, lo que ha supuesto el despoblamiento y la crisis demográfica de bastantes municipios rurales, cuyos hogares vivían de las actividades agropecuarias. En este sentido, si queremos priorizar la fijación y renovación de población en el territorio rural debemos cambiar con urgencia el modelo de agricultura y ganadería hacia una lógica económica en la que predomine la cooperación entre las explotaciones familiares, así como la sostenibilidad ambiental de sus recursos, la calidad en sus producciones y la comercialización a través de sus asociaciones. 


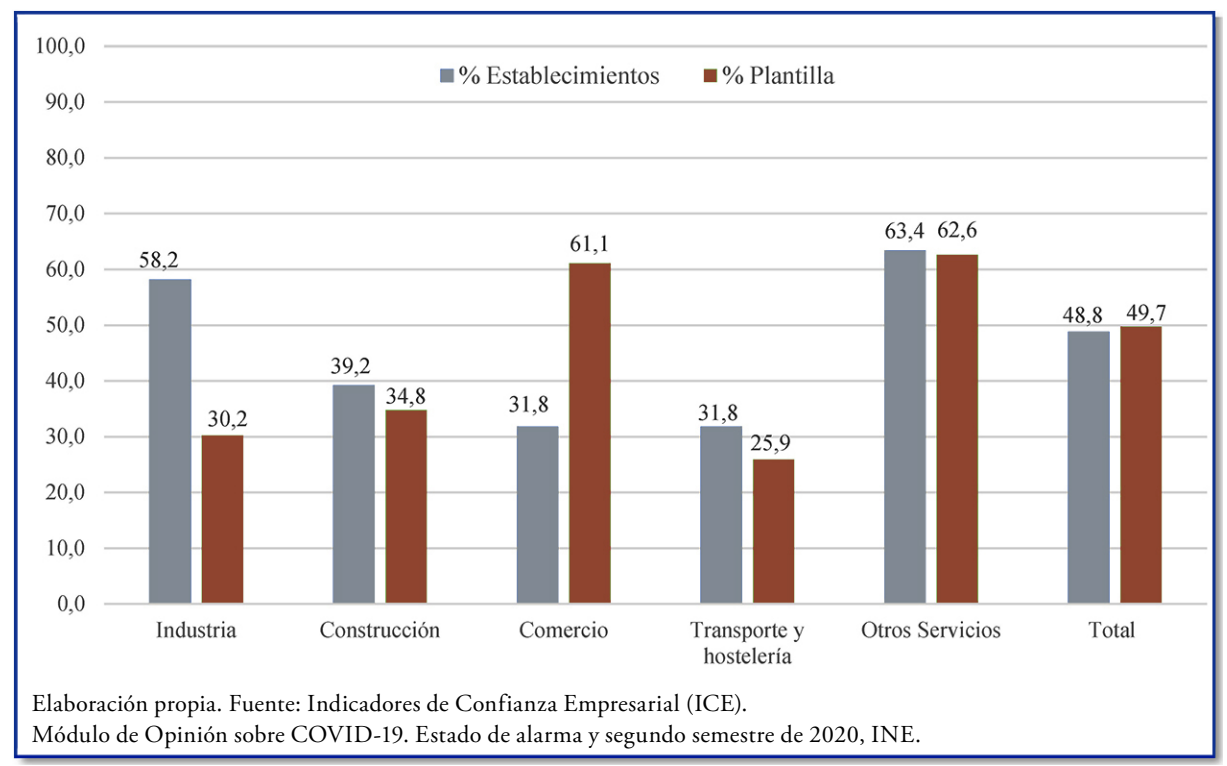

Gráfico 13. Porcentajes de establecimientos y de plantilla que han utilizado el teletrabajo durante el estado de alarma en España según sectores de actividad durante el segundo semestre de 2020.

maltrecho y olvidado territorio rural que sufre la crisis demográfica, que se debería aprovechar. Según los resultados de la encuesta de Indicadores de Confianza Empresarial del INE referida al segundo semestre de 2020 (ver gráfico 13), casi la mitad de los establecimientos en España $(48,8 \%)$ han utilizado el teletrabajo durante el estado de alarma, afectando a la mitad de la plantilla (49,7\%), lo que supone un importante crecimiento en el uso del teletrabajo con respecto al momento anterior al estado de alarma (14,8\% de establecimientos y 32,1\% de las plantillas). Además, casi la tercera parte de los establecimientos (32,2\%) que optaron por el teletrabajo durante el estado de alarma declara que lo mantendrá en el futuro (al menos durante los seis meses próximos).

Los representantes de las administraciones públicas, del empresariado y de las organizaciones sindicales deberían consensuar, dentro del marco legal y fiscal que regule e incentive el teletrabajo, un objetivo y línea estratégica de actuación que desarrolle su potencialidad para contribuir al repoblamiento y rejuvenecimiento de los municipios rurales. En este sentido, es necesario desarrollar un plan de inversiones públicas que garanticen un acceso de calidad a internet de los municipios y comarcas rurales que actualmente disponen de una mala e insuficiente conectividad digital, para que puedan acoger el teletrabajo que se deslocalice desde el medio urbano hacia el rural. Por consiguiente, es fundamental reducir la brecha digital que segrega y margina al territorio rural. 
Paralelamente, la deslocalización del teletrabajo urbano en cantidades significativas hacia municipios rurales tendría consecuencias beneficiosas en las ciudades y áreas metropolitanas, ya que ayudaría a descongestionarlas de residentes, actividades y del tráfico motorizado, reduciendo la contaminación ambiental y el calentamiento del clima local que sufren. Asimismo, la emigración de urbanitas al medio rural ayudaría a moderar los precios de la vivienda, de las oficinas y de los locales comerciales en las urbes, además de desahogar de usuarios a los servicios colectivos y el espacio público, contribuyendo a que fuesen un entorno más habitable y saludable.

En definitiva, necesitamos unas políticas alternativas que apoyen realmente el retorno de las y los emigrantes y, a su vez, la inmigración de 'neorrurales' de las cohortes económicamente activas, tanto nacionales como extranjeros. Esto es, de urbanitas que sufren un malestar psicosocial por verse obligados a mal vivir en unas urbes artificiosas y contaminantes, donde la precariedad, la segregación y la deshumanización proliferan. Para los cuales, el teletrabajo bien podría ser la forma laboral para liberarse y comenzar el buen vivir en el territorio rural. Un movimiento neorrural (Trabada y Rodríguez, 1991) que podrá focalizar sus deseos y necesidades personales y grupales, buscar y construir en el territorio rural, con mayor libertad e igualdad, unos estilos de vida más satisfactorios, saludables, convivenciales y sostenibles, a la vez que realizará importantes aportaciones demográficas, económicas y socioculturales a un mundo rural que quiere y lucha por sobrevivir.

Recibido: 23 de julio de 2020; ACEptado: 27 de octubre de 2020 


\section{REFERENCIAS BIBLIOGRÁFICAS}

Camarero, L. y Sampedro, R. (2016). «Inmigrantes, estrategias familiares y arraigo: las lecciones de la crisis en las áreas rurales». Migraciones. Publicación del Instituto Universitario de Estudios sobre Migraciones, 40: 3-31, recuperado de https://revistas.comillas.edu/index.php/ revistamigraciones/article/view/7561. Última consulta: 20/07/2020.

Camarero, L. y Sampedro, R. (2008). «¿Por qué se van las mujeres? El continuum de movilidad como hipótesis explicativa de la masculinización rural». Revista Española de Investigaciones Sociológicas (Reis), 124: 73-105, recuperado de http://www.reis.cis.es/REIS/PDF/ REIS_124_031222873178255.pdf. Última consulta: 20/07/2020.

Del Molino, S. (2016). La España vacía. Viaje por un pais que nunca fue. Madrid: Turner.

Hardin, G. (2005). «La tragedia de los comunes». Polis Revista Latinoamericana, 10: 1-14, recuperado de http://journals.openedition.org/polis/7603. Última consulta: 20/07/2020.

IвÁñez, J. (1991). El regreso del sujeto. La investigación social de segundo orden. Santiago de Chile: Editorial Amerinda.

Illich, I. (1985). La convivencialidad. México: Joaquín Mortiz/Planeta, recuperado de http://ivanillich.org.mx/convivencial.pdf. Última consulta: 20/07/2020.

INE (2020). Indicador de Confianza Empresarial (ICE). Módulo de Opinión sobre el Impacto de la Covid-19. Estado de alarma y segundo semestre de 2020. Nota de prensa 10/07/2020, recuperado de https://www.ine.es/daco/daco42/ice/ice_mod_covid_0320.pdf. Última consulta: 20/07/2020.

IzQuierdo, J. (2002). Manual para Agentes de Desarrollo Rural: Ideas y propuestas para moverse entre la conservación del patrimonio y el Desarrollo Local. Madrid: Ediciones Mundi-Prensa.

Llamazares, J. (1988). La lluvia amarilla. Barcelona: Seix Barral.

Naredo, J. (2006). Raíces económicas del deterioro ecológico y social. Más allá de los dogmas. Madrid: Siglo XXI de España Editores, SA.

Rodríguez-Villasante, T. (2009). "Conjuntos de acción y participación rural». Documentación Social, 155: 41-56.

Santos, I. (1996). «Envejecimiento demográfico: diferencias por género». Revista Española de Investigaciones Sociológicas (Reis), 73: 177-190, recuperado de http://www.reis.cis.es/REIS/PDF/ REIS_073_11.pdf. Última consulta: 20/07/2020.

Sevilla, E. (2006). De la Sociología Rural a la Agroecología. Barcelona: Icaria.

TRABADA, E. (2020). Encuesta a residentes de 16 y más años en pueblos o municipios rurales e Informe de la población y la economía de seis zonas o comarcas de actuación de COCEDER. Consultora Emic-Etic. Valladolid: Confederación de Centros de Desarrollo Rural (COCEDER).

Trabada, E. (2019). Estudo sociolóxico sobre a crise demográfica na Pastoriza: Análise e estratexia de desenvolvemento local. Consultora Emic-Etic. A Pastoriza (Lugo): Alcaldía.

Trabada, E. (dir.) y Renes, V. (coord.) et al. (2007). Estudo sociolóxico sobre o territorio rural de Galicia. Consultora Emic-Etic. Santiago de Compostela: Fundación FOESSA, Cáritas de Galicia e Obra Social da Fundación CaixaGalicia.

Trabada, E. y Rodríguez, B. (1991). «De la ciudad al campo: el fenómeno social neorruralista en España». Política y Sociedad, 9: 73-86, recuperado de https://dialnet.unirioja.es/ejemplar/93149. Última consulta: 20/07/2020.

Van de KaA, DJ. (1987). «Europe’s Second Demographic Transition». Population Bulletin, 42(1): 1-59.

VÁzQuez, Antonio (2007). «Desarrollo endógeno. Teorías y políticas de desarrollo territorial». Investigaciones Regionales $=$ Journal of Regional Research, 11: 183-210, recuperado de https:// dialnet.unirioja.es/ejemplar/179583. Última consulta: 20/07/2020. 